\title{
Clinical electrophysiology of the optic nerve and retinal ganglion cells
}

\author{
Oliver R. Marmoy $\mathbb{D}^{1,2,3} \cdot$ Suresh Viswanathan ${ }^{4}$
}

Received: 17 March 2021 / Revised: 11 May 2021 / Accepted: 19 May 2021 / Published online: 11 June 2021

(c) The Author(s) 2021. This article is published with open access, corrected publication 2021

\begin{abstract}
Clinical electrophysiological assessment of optic nerve and retinal ganglion cell function can be performed using the Pattern Electroretinogram (PERG), Visual Evoked Potential (VEP) and the Photopic Negative Response (PhNR) amongst other more specialised techniques. In this review, we describe these electrophysiological techniques and their application in diseases affecting the optic nerve and retinal ganglion cells with the exception of glaucoma. The disease groups discussed include hereditary, compressive, toxic/nutritional, traumatic, vascular, inflammatory and intracranial causes for optic nerve or retinal ganglion cell dysfunction. The benefits of objective, electrophysiological measurement of the retinal ganglion cells and optic nerve are discussed, as are their applications in clinical diagnosis of disease, determining prognosis, monitoring progression and response to novel therapies.
\end{abstract}

\section{Introduction}

The optic nerve and retinal ganglion cells (RGCs) are essential in the transmission of visual information through the intracranial pathway to the striate/primary visual (V1) cortex. Diseases of the optic nerve and RGCs therefore can lead to significant visual impairment and may be a primary pathology or secondary consequence of other conditions. Whilst ophthalmic imaging and psychophysical tests can provide insight into structural and behavioural sequelae of optic nerve dysfunction, functional assessments through electrophysiology provide an objective and quantitative approach to characterise these deficits directly at the level of optic nerve and RGCs.

The electrophysiology of the optic nerve and RGCs has been well established through the Visual Evoked Potential (VEP) and Pattern Electroretinogram (PERG), and more recently with the Photopic Negative Response (PhNR)

Oliver R. Marmoy

o.marmoy@nhs.net

1 Clinical and Academic Department of Ophthalmology, Great Ormond Street Hospital for Children, London, UK

2 UCL-GOS Institute for Child Health, University College London, London, UK

3 Manchester Metropolitan University, Manchester, UK

4 College of Optometry, State University of New York, New York, NY, USA alongside other specialised techniques like the multifocal electroretinogram, PERG and VEP (mfERG, mfPERG, mfVEP) to provide a more detailed evaluation of the retinal locus and spatial extent of cellular dysfunction. These prospects are promising in the phenotyping and characterisation of optic nerve disease where other clinical information may not provide sufficient information.

In this review, we discuss the electrophysiological basis of optic nerve and RGC disease and its role in investigating the site and extent of dysfunction to complement structural and psychophysical findings in disease. We start by defining our search strategy, followed by a description of the main electrophysiological techniques used to assess the optic nerve and RGCs, including their stimulus and recording parameters. We then discuss the clinical applications of these techniques to diseases or conditions affecting the optic nerve and RGCs, lastly concluding with diagnostic aids and dilemmas commonly encountered in ophthalmic and neuroophthalmic practice.

\section{Methods}

A comprehensive search of literature on Medline (PubMed), ScienceDirect, the Cochrane Library was performed by the authors. Search terms included respective diagnostic tests and their related terms or abbreviations (i.e. Visual* evoked potential OR VEP OR Visual* evoked response) against the clinical condition of interest (i.e. Optic neuritis OR demyelin* OR papillitis OR multiple sclerosis). Broad 


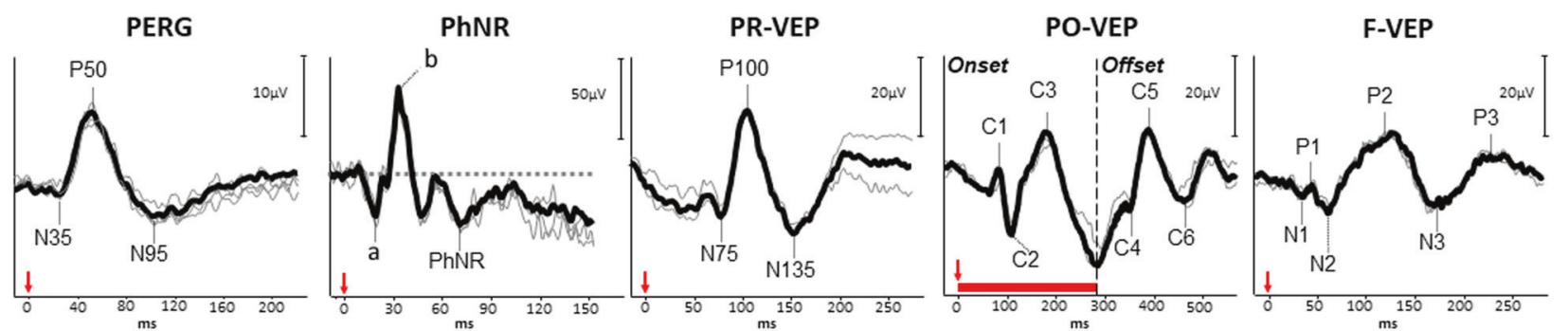

Fig. 1 Illustrative waveform examples for the major electrophysiological tests in the assessment of optic nerve and retinal ganglion cell (RGC) function. In all panels, relative amplitudes are observed in the top right, with timings seen on the $X$-axis. The left most panel shows the transient pattern electroretinogram (PERG), following the stimulus (red arrow) an initial N35 negativity is seen followed by the main positivity (P50) and large later negativity (N95). The photopic negative response (PhNR) is next seen, recorded to a diffuse flash stimulus (red arrow). The a- and b-waves of the ERG are

search terms were used to capture a wide range of literature. In circumstances where standard search terms retrieved few results, search terms were broadened to include more general electrophysiological terms (i.e. electrophysio* OR electroret* or electrodiag*). No limits were applied in relation to publication dates but only articles available in the English language were reviewed. Each article had a full-text review and was critically appraised by the authors. Additional review of references within qualifying publications was also undertaken in search of any further published works relevant to this review. The main interests to this review were studies employing electrophysiological techniques within the main clinical conditions, from which the authors used their clinical experience to determine the most relevant and clinically useful findings to this review. Animal studies were generally excluded unless of particular importance to underpinning science or methodology.

\section{Electrophysiological tests of optic nerve and retinal ganglion cell function}

\section{Visual evoked potential (VEP)}

The VEP is an important clinical test for assessing the functional integrity of the visual pathway from the retina to the striate cortex (primary visual cortex or V1). As such, this test has been extensively used in the evaluation of ophthalmic, neurological and systemic disease. The VEP is produced from activation of cortical neurons in response to afferent pathway stimulation, which is recorded with electrodes placed over the occiput. Typically, VEPs are recorded to a high contrast pattern or diffuse flash stimuli. For pattern VEPs, a checkerboard or grating stimulus is reversed in contrast over time whilst maintaining a constant mean luminance (PR-VEP), or alternatively the seen of the typical flash ERG, followed by the late negativity known as the PhNR. In the central panel the pattern reversal VEP (PR-VEP) is seen, a triphasic response with N75, P100 and N135 peaks respectively. The pattern onset-offset VEP (PO-VEP) response is seen to a longer stimulus (red bar), the initial response comprises the onset VEP of C1-C3 components, later followed by the offset VEP C4-C6 components. Lastly the flash VEP (F-VEP) is seen to a diffuse flash stimulus (red arrow), followed by a series of positive-negative deflections, with the major N2 and P2 peaks observed.

checkerboard appears and disappears on a background with the same mean luminance known as the pattern onset-offset VEP (PO-VEP), which provide information regarding the function of the macular pathways. Flash VEPs (F-VEP) are typically recorded to a strobe or LED flash stimulator and is useful in the examination of the generalised visual pathway function, particularly in eyes with poor optical quality where retinal image contrast is degraded.

The typical PR-VEP waveform comprises a triphasic response, with components named according to their relative polarity and peak-time. A major positive peak is seen around $100 \mathrm{~ms}$ (P100), with preceding and following negativities around $75 \mathrm{~ms}$ (N75) and $135 \mathrm{~ms}$ (N135) respectively (Fig. 1). The PO-VEP waveform is more complex, with onset $\mathrm{C} 1, \mathrm{C} 2$ and $\mathrm{C} 3$ components which are more variable between individuals and change in shape during the normal lifespan [1], with offset responses typically demonstrating a triphasic waveform similar to the PR-VEP (Fig. 1). The F-VEP waveform is also complex comprising of multiple peaks and troughs named N1, $\mathrm{P} 1, \mathrm{~N} 2, \mathrm{P} 2, \mathrm{~N} 3$ and $\mathrm{P} 3$ respectively. The major positive peak (P2) and preceding negativity (N2) are most commonly used in clinical assessment as these waveforms are most robust. The interpretation of responses is performed by assessing the response amplitude (from the preceding negativity or baseline), peak-time/latency, morphology and transoccipital distribution. The amplitude and latency of responses should be compared to reference values, which are collected or validated to the local laboratory environment as with all clinical visual electrophysiology techniques. Generally, different conditions of the optic nerve or RGCs may affect response amplitude or latency preferentially, the VEP has a large macular contribution and can be affected by anything upstream in the visual pathway, for example a maculopathy may degrade responses as well as primary RGC disease. Abnormalities of the VEP should therefore always be explored with the PERG to elaborate on the site and extent of dysfunction. 
There are regularly reviewed international standards for performing clinical VEPs [2]. Whilst these standards provide the minimum recording requirements for performing a VEP, it is emphasised that these are a set of minimum standards and those performing VEPs should expand on these standards with additional protocols to address more complex clinical questions [3]. Interpretation of VEPs should rarely be used in isolation as this could lead to misdiagnosis. For example, even in suspected neurological dysfunction an abnormality of a P-VEP is not specific to optic nerve disease, as the response is subject to good macular integrity and therefore assesses the visual pathway from the macula to striate cortex and should be explored with the PERG where abnormal.

The PR-VEP has relatively low inter- and intra-subject variability which has facilitated its clinical use, whereas the PO-VEP and F-VEP can be more variable between individuals and therefore limits their clinical applications [4-7]. Nevertheless, these stimuli do have benefits in the assessment of patients with poor vision, low cooperation, detection of intracranial pathway dysfunction and inter-ocular differences. PR-VEPs are largely dominated by input from the macula, with expanded representation of the central field, which is scaled topographically known as cortical magnification [8, 9]. As such, the PR-VEP shows a Ushaped spatial tuning function against check width, alongside being modulated by stimulus luminance, contrast and field size [10]. These properties can be used to a great advantage in some circumstances to exceed ISCEV recording standards, for example recording PR-VEPs to a range of check widths or to reduced stimulus contrast can increase diagnostic sensitivity, with VEP abnormalities sometimes preceding structural change in optic nerve dysfunction, which will be discussed in more detail later in this review [11-15].

It should also be noted that the pattern VEP in clinical practice is typically recorded to an achromatic pattern stimulus, but it is possible to use chromatic stimuli to assess parvocellular and koniocellular parallel pathways of the visual system using red-green or blue-yellow stimuli respectively. Chromatic VEPs have been used to identify colour processing dysfunction in demyelinating disease [16-18], LHON [19], Glaucoma [20], Parkinsons disease [21] and congenital colour blindness [22]. Their use is intriguing in conditions of the optic nerve and RGCs causing dyschromatopsia or more selective RGC pathway deficits. However, the stimuli required for testing are technically challenging to achieve, requiring reproducible spectral stimulus properties, isoluminance, alongside age- and ethnicity-controlled reference data to allow for macula pigment and the effects on cone fundamentals which has overall limited their widespread clinical use [23].

\section{Pattern electroretinogram (PERG)}

The PERG provides information regarding macula and RGC function and thus has a role in the investigation of both ophthalmic and neurological disease. The PERG is able to delineate the site of dysfunction in those patients with abnormal PVEPs, quantify the extent of dysfunction, and to provide spatial information regarding the functional visual field. The transient PERG is typically produced to a reversing checkerboard or grating stimulus with a constant mean luminance presented at $\sim 4 \mathrm{rev} / \mathrm{sec}$, with the generated response comprised of a sometimes ill-defined small initial negativity (N35), followed by a major positivity around 50 $\mathrm{ms}$ (P50) and large later negativity around $95 \mathrm{~ms}$ (N95) (Fig. 1). The P50 component has contributions from both the outer- as well as inner-retinal neurons, including the RGCs. Conversely, the N95 component is solely generated by spiking activity of RGCs and is sensitive to retinal nerve fibre degeneration and RGC loss [24, 25].

The PERG is a small signal and typically recorded with corneal electrodes, which do not affect the visual optics. Skin electrodes are not routinely used due to the poor signal-to-noise ratio, but do have advantages in those unable to tolerate corneal electrodes such as children [26]. Since the PERG is elicited in response to contrast modulation of a pattern stimuli, optimal refractive correction is necessary to ensure that the retinal image contrast is not degraded. The PERG is more sensitive to contrast changes and defocus than the PVEP, likely due to the PERG being a reflection of direct retinal activity to pattern stimuli, whereas for the PVEP several post-retinal processes occur which have some modulation and compensation for low contrast and defocus, alongside cortical magnification, making the PVEP more robust than the PERG to these changes. The PERG is typically recorded to a standard $15^{\circ}$ field size, but an additional large field of $30^{\circ}$ may also be used which can provide further topographic information of paramacular function [27]. Furthermore, simultaneous recording alongside a PR-VEP allows control for fixation and defocus, therefore it can be useful in patients with functional visual loss. The PERG to high temporal frequencies (typically $>10 \mathrm{rev} / \mathrm{sec}$ ) generates a steady-state response, which is not widely used in clinical practice but does have some clinical applications in conditions like Glaucoma (reviewed elsewhere within this issue). As with the VEP, there are international minimum standards for recording the clinical PERG [28].

The interpretation of the PERG provides assessment of the overall outer retinal and RGC/optic nerve pertaining to the macula. A reduction in amplitude of the P50 component with normal or slightly delayed peak-time and preservation of the N95:P50 ratio is reflects dysfunction anterior to the RGCs (i.e. cone photoreceptors or bipolar cells) or reduced retinal image 


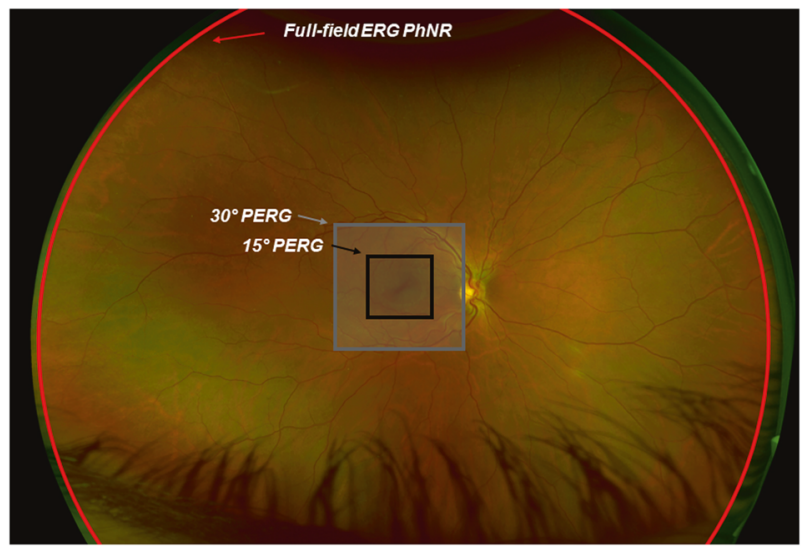

Fig. 2 Stimulus conditions for the pattern ERG (PERG) and Photopic Negative Response (PhNR) relative to the retinal topography from an optomap image. This figure illustrates the full-field nature of the $\mathrm{PhNR}$ (red circle) being a pan-retinal response, whereas the PERG is recorded to a central stimulus subtending $30^{\circ}$ (grey box) or $15^{\circ}$ (black box) of the central retina respectively.

contrast. Conversely, a predominant reduction in the N95 amplitude with an intact P50, which reduces the N95:P50 ratio, is characteristic of RGC and optic nerve dysfunction (Fig. 1) [25]. Importantly however, in severe RGC disease there can be reduction in P50 amplitude and shortening of peak-time, as the P50 component has some contributions from RGCs [24]. The P50 component should therefore not be extinguished unless there is concomitant dysfunction anterior to the RGCs (i.e. from a maculopathy). A normal PERG but abnormal PR-VEP localises dysfunction to outside of the central RGCs or posteriorly along the visual pathway.

\section{Photopic negative response (PhNR)}

The PhNR is a slow negative potential that follows the $b$-wave of the light-adapted flash ERG and originates as a consequence of spiking activity of inner-retinal neurons, predominantly the RGCs [29]. While the PhNR can be elicited with the ERG stimuli used in standard clinical testing [30], the optimal stimulus that elicits the maximal amplitude reduction in RGC dysfunction is a red flash on a rod-saturating blue background $[31,32]$. The PhNR amplitude is typically measured at its trough (or at a fixed time in the range of $65-75 \mathrm{~ms}$ after the onset of the test flash) from the baseline [33] (Fig. 1). Other methods of evaluating the PhNR amplitude includes measurement from the trough to the peak of the preceding b-wave or expressing this value as a ratio of the b-wave amplitude [29, 34-36]. The PhNR is typically elicited with a full-field flash stimuli and consequently reflects the summed activity of RGCs across the entire retina and cannot determine the spatial localisation of the RGC defect. Typical recording parameters are included in the ISCEV extended protocol [33]. However, having the responses of retinal bipolar cells and cone photoreceptors within the same ERG waveform is useful to discern the functionality of the neurons that provide input to the RGCs. In addition, since the visual stimulus is diffuse, the responses are not affected by optical defocus and thus refractive correction is not required, furthermore this may aid in the identifying generalised RGC loss across the retina while the PERG is normally limited to the macula (Fig. 2).

\section{Multifocal techniques}

The mfERG employs computational techniques that allow obtaining sub-microvolt focal ERG responses simultaneously from multiple retinal areas within a relatively short recording time [37]. The mfERG responses are organised in kernels with responses increasing in their degree of complexity with increasing kernel orders. The first-order kernel responses that are typically analysed with standard clinical mfERG testing [38] does not contain obvious RGC responses. However, more sophisticated algorithms allow the separation of an Optic Nerve Head Component from the first-order kernel responses which in turn is abolished in eyes with optic nerve abnormalities [39]. Variations from standard mfERG stimulation techniques can allow recording PhNRs from discrete retinal regions [40, 41].

The multifocal recording technique can be combined with the contrast reversal of pattern stimulus elements, scaled in size across the visual field to reflect the cortical magnification factor, to enable recording focal VEP responses from the visual cortex $[42,43]$. This technique is commonly referred to as the multifocal VEP (mfVEP) and allows topographical analysis of the VEP through the detection of regional changes in amplitude and waveform delay, that may not be reflected in the gross potentials measured with conventional VEP recording.

Similarly, mfERG recordings to a contrast reversal of pattern stimuli from discrete retinal regions termed the multifocal PERG (mfPERG) demonstrate second order kernel responses with the waveform shape resembling that of the conventional transient PERG for slower stimulation sequences [44]. There is compelling evidence to support the notion that the mfPERG response originates from activity of inner-retinal neurons and is likely generated at the optic nerve head [45, 46]. While multiple studies have demonstrated the reduction of mfPERG amplitude in several disease conditions, its ability to detect focal defects as opposed to a generalised reduction may be disease specific [45, $47-$ $52]$.

\section{Other methods}

Neuronal contributions to the full-field flash ERG can also be elicited under dark-adapted conditions. The Scotopic Threshold Response (STR) is an ERG response with 
negative polarity and a slower time-course than the PhNR that can be elicited with very dim flashes of light, close to the absolute visual threshold under strictly dark-adapted conditions $[53,54]$. The STR reflects a combination of RGC and amacrine cell responses mediated by the rod pathway. This ERG measure has not gained clinical utility mainly due to dark-adaptation requirements.

The oscillatory potentials (OPs) are high frequency responses predominantly of amacrine cell origin [55, 56] typically measured in the range of $70-300 \mathrm{~Hz}$ in the standard clinical ERG [30]. The OPs manifest as wavelets on the ascending limb of the b-wave of the flash ERG that can be seen for ERG measurements under both dark- and lightadapted conditions. While the OPs are generally associated with amacrine cells, the oscillations themselves are considered to be modulations of bipolar cell responses by inhibitory feedback of amacrine cells [57] and is not further discussed in this review.

\section{Clinical applications}

\section{Hereditary optic neuropathies and primary retinal ganglion cell disease}

Autosomal Dominant Optic Atrophy (ADOA) is a degenerative condition of the optic nerve that affects both eyes and is characterised by gradual deterioration of vision, typically starting in early childhood [58-60]. Mutation of the OPA1, OPA3, genes that code for proteins associated with electron transport and ATP synthesis in the mitochondrial inner membrane and three loci (OPA4, OPA5, OPA8) underlie the genetic defect in ADOA [58]. In addition, defects with other loci like OPA2, OPA6 and OPA7 genes underlie $\mathrm{x}$-linked and recessive inheritance of optic atrophy [58].

The severity of visual impairment is variable from a mild reduction in visual acuity to blindness and around 20\% of patients with ADOA also manifest neurological symptoms outside the visual system [58]. ADOA patients develop visual field defects that typically arise as central or centrocecal scotomas, with commensurate peripapillary RNFL thinning on OCT measurements alongside optic disc pallor [61]. Visual rehabilitation with low vision aids and genetic counselling currently remain the focus for management of this condition [61], although there is promise in animal models for gene therapy [62].

Visual electrodiagnostic techniques complement the behavioural assessment of visual function in ADOA. Specifically, it pinpoints the functional deficit to the level of the RGCs and the optic nerve and is also quite useful as a reliable objective measure of visual function when behavioural testing is unreliable, for example in children. PR-
VEP waveforms are delayed with reduced amplitude in ADOA patients with mild to moderate severity and can be extinguished in advanced cases [63-65]. Furthermore, the waveform may become bifid or of a 'p-n-p' morphology due to enhancement of paramacular PR-VEP components which can occur with reduced central visual field sensitivity [66-68]. The N95 component of the PERG is reduced but the P50 component is mostly normal or reduced in severe cases where the N95 is extinguished. Analysis of the PRVEP changes in combination with the alteration of the N95 and P50 components of the PERG recordings can confirm the locus of the functional deficit in ADOA to the level of RGCs and the optic nerve. The PhNR of the flash ERG is reduced in ADOA with sparing of the a- and b-waves, reiterating the RGCs as the locus of the functional deficit $[69,70]$. While the PhNR for both full-field and focal flash ERG recordings are reduced in ADOA, the PhNR recorded to focal stimulation demonstrates a higher sensitivity for detection of ADOA, approaching the sensitivity estimates of the PERG [70]. These findings highlight the importance of using focal stimulation for optimal electrophysiological testing of ADOA patients who typically demonstrate central visual field defects.

Leber's hereditary optic neuropathy (LHON) is another condition characterised by the selective degeneration of RGCs due to mutations associated with genes encoding for mitochondrial proteins involved in oxidative phosphorylation [71]. In majority of the cases, the genetic defect in LHON is associated with the mutation of mitochondrial DNA $11778 \mathrm{G}>\mathrm{A}, 14484 \mathrm{~T}>\mathrm{C}$ and $3460 \mathrm{G}>\mathrm{A}$ [72]. The condition is characterised by bilateral painless reduction in visual acuity with development of centrocecal scotoma resulting from papillomacular nerve fibre bundle degeneration and is typically seen in men in the second or third decade of life [60, 61]. Retinal and circumpapillary telangiectasia, increases in RNFL thickness and pseudooedema of the optic disc can be observed prior to symptomatic vision loss [73-75]. Optic disc pallor can be observed subsequently starting with the inferotemporal quadrant with progressive RNFL thinning [75]. While visual prognosis was generally considered to be poor in symptomatic LHON cases, newer treatments such as Idebenone have been demonstrated to improve visual outcomes through stimulation of ATP synthesis and free radical scavenging in mitochondria [76]. Further, at the time of writing early studies of gene therapy appear promising in humans [77, 78].

In LHON cases with clinically distinct optic atrophy the P100 component of the PR-VEP, if not extinguished, is delayed with reduced amplitude and the PERG demonstrates reduced amplitude of the N95 component [79-81]. PR-VEP and PERG abnormalities can manifest in affected eyes prior to clinically visible temporal pallor of the optic 
disc, with PR-VEP alterations being more prevalent than PERG alterations [81]. Interestingly, the amplitude of the N95 component of the PERG is selectively reduced in eyes of some patients classified as LHON carriers, based on incomplete penetrance in the absence of VEP abnormalities, leading to question whether the PERG amplitude reduction represents subclinical changes and could serve as a marker for those who may convert to the acute phase [80]. Indications of subclinical changes in some LHON carriers is also supported by abnormal findings with specialised psychophysical testing [19, 82]. The PhNR amplitude is also reduced in LHON patients with sparing of the a- and bwaves localising the functional deficit to the RGCs with measurements from baseline as opposed to the peak of the b-wave being more sensitive [19, 83, 84]. As with the PERG, the PhNR amplitude is also reduced in the eyes of some LHON carriers with the amplitudes showing a graded effect with RNFL thickness [83, 84]. In addition to its use in the assessment of RGC function at the time of diagnosis, visual electrophysiology techniques are also useful in assessing the efficacy new treatments for LHON [76]. An illustrative case of a patient with LHON is seen in Fig. 3.

There are several rare inherited disorders that include visual dysfunction where the PhNR is reduced and can assist in the simultaneous evaluation of optic nerve and retinal function. Hereditary Motor and Sensory Neuropathy Type VI is a condition where the PhNR is reduced. It is a severe form of Charcot-Marie-Tooth disease type 2A resulting from mutations in the MFN2 gene that codes for proteins in the outer mitochondrial membrane and the condition is characterised by peripheral axonal neuropathy with up to $20 \%$ of patients with the severe form of this condition also manifesting optic atrophy [85, 86]. Patients with late onset visual loss have a better chance of visual acuity improvement compared to patients with early onset of visual loss [85]. However, even patients with late onset visual loss who regain near normal visual acuity can demonstrate a severe reduction in the PhNR amplitude when the $a-$ and $b$-waves are in the normal range suggesting the value of electrodiagnostic testing in understanding the full extent of the optic nerve functional deficit [87]. Interestingly, PR-VEP abnormalities have also been observed in Charcot-Marie Tooth disease of other genotypes, some without optic atrophy [88-91].

EAST syndrome is another genetic disorder where the PhNR amplitude is reduced [92]. This syndrome characterised by Epilepsy, Ataxia, Sensorineural deafness, and Tubulopathy resulting from a mutation of the KCNJ10 gene coding for Kir4.1, an inward rectifying potassium channels in the brain, inner ear and kidney [93]. These inward rectifying potassium channels are also expressed on retinal glial cells, which play a role in the siphoning and redistribution of potassium ions in the extracellular space [94]. A selective reduction in the $\mathrm{PhNR}$ amplitude in addition to providing confirmation of a deficit in retinal function in symptomatic patients reiterates previous hypotheses of the PhNR ERG potential also reflecting a glial mediated current secondary to extracellular potassium, resulting from RGC activity [29, 95]. Thus, in conditions such as EAST syndrome when the PhNR amplitude reduction can be prone to more than one interpretation, additional tests such as the PERG and VEP will be useful to assess the full extent of RGC and optic nerve function.

\section{Compressive, infiltrative, toxic and nutritional optic neuropathies}

Compressive optic neuropathies or those secondary to space occupying lesions can cause significant disruption to optic nerve and RGC physiology. Intracranial tumours may affect any portion of the visual pathway and, as such, the VEP is well suited to provide assessment in localising the pathway lesion and information of pathway integrity. Whilst this review focuses on conditions affecting the optic nerve and RGC's, it is prudent to discuss lesions affecting the entire visual pathway to the striate cortex which may later inflict dysfunction of the optic nerve or RGCs, for example due to retrograde degeneration of RGCs. As such, VEPs are a useful tool in the examination of the intracranial visual pathway especially when used in conjunction with the PERG and/or PhNR.

When utilising a transoccipital array of electrodes, one can use the lateralising features of VEP distributions to identify chiasmal and retrochiasmal pathway dysfunction. The lateralisation of the flash VEP has been demonstrated in both chiasmic and retrochiasmic lesions. Seminal studies using F-VEP in patients with homonymous field defects have demonstrated the major positive peak to become altered in lesions relating to the underlying field defect $[96,97]$. As such, in lesions of the chiasm, one can observe a 'crossed' asymmetry of pattern or F-VEPs, whereby the transoccipital asymmetry will alter its lateralisation dependent on the eye stimulated [98]. These lateralising features have been adopted clinically to identify both chiasmal misrouting and a paucity of functional crossing fibres at the chiasm resulting from developmental or lesion related deficits of the chiasm [98-101]. The lateralising features of the VEP can be also used in retrochiasmic lesions using a flash or pattern stimulus to produce an 'uncrossed' asymmetry (i.e. a transoccipital asymmetry which remains static regardless of the eye stimulated) [102-106]. However, hemifield PR-VEPs are a far more advantageous method for investigating these intracranial visual pathway abnormalities [107]. One must be aware that, with a large stimulus field, large check size and a mid-frontal reference electrode, 


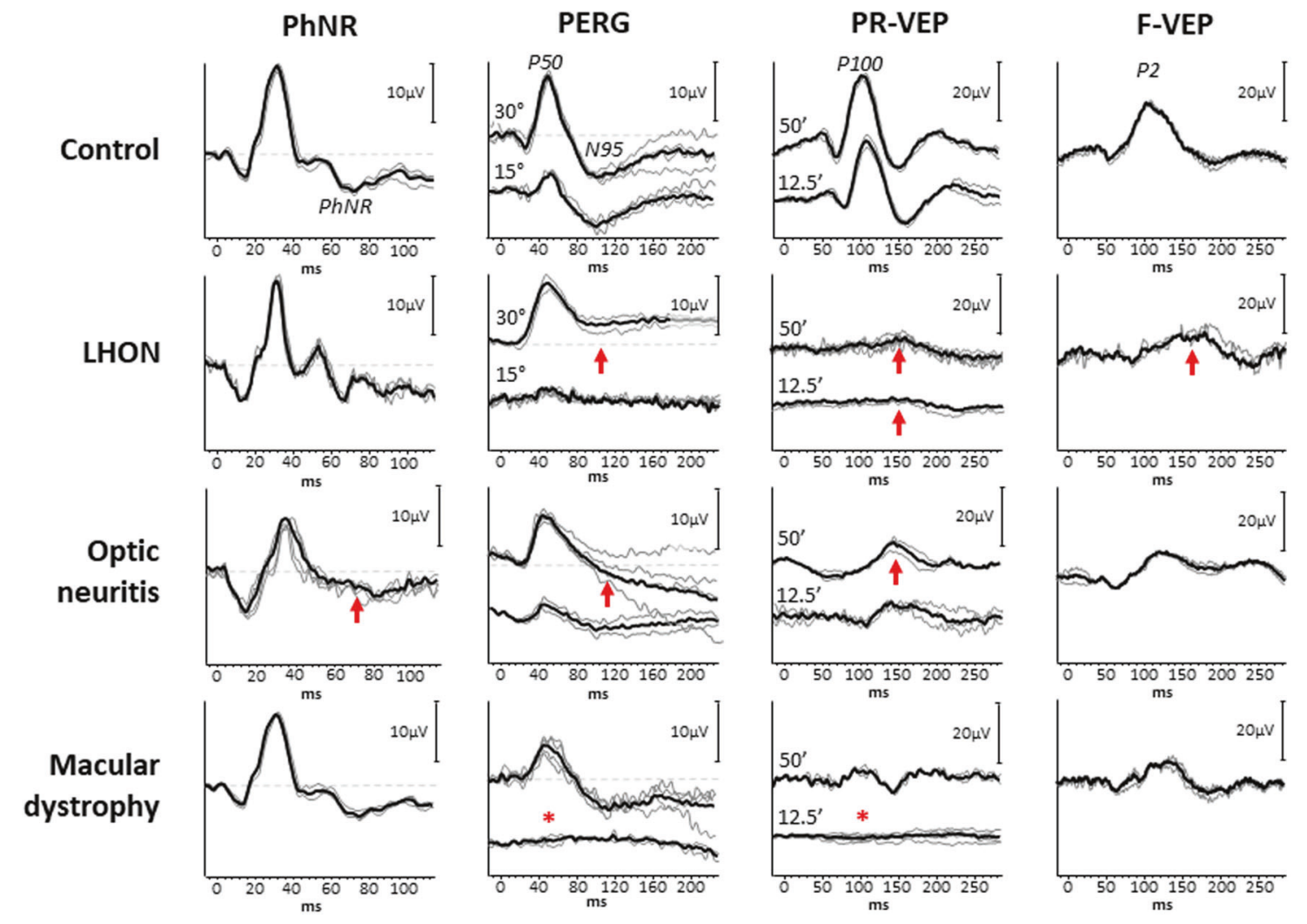

Fig. 3 Illustrative case series demonstrating the electrophysiological findings in a healthy subject, and affected eyes of patients with Lebers Hereditary Optic Neuropathy, Optic Neuritis and Macular dystrophy respectively. The top row is used for reference, to demonstrate the normal findings of the photopic negative response (PhNR), pattern electroretinogram (PERG) (to $30^{\circ}$ and $15^{\circ}$ fields), pattern reversal visual evoked potential (PR-VEP) (to $50^{\prime}$ and $12.5^{\prime}$ check widths) and flash visual evoked potential (F-VEP). LHON: The PERG demonstrates normal P50 components but markedly abnormal N95 components which do not fall below the baseline, to the $15^{\circ}$ field the P50 is also reduced with early peak-time. The PR-VEP is severely degraded to both check widths, with only a small response to large check widths, with the F-VEP broad and slightly low amplitude but preserved. The PhNR is relatively preserved, although does not fall below the a-wave. Overall, this indicates marked bilateral retinal ganglion cell (RGC) and optic nerve dysfunction, with some

the paradoxical lateralisation phenomenon occurs with PRVEPs, whereby the major positivity is observed over the occiput contralateral to the generating hemisphere [108]. This phenomenon is not observed in the pattern onset VEP, but has been observed in the pattern offset VEP [109]. Selective stimulation of the right- or left-hemifield can isolate the visual pathway contributions and allow localisation of the pathway dysfunction site, for example a bitemporal hemifield loss in the PR-VEP would suggest chiasmal dysfunction, whereas a homonymous left hemifield loss would indicate a right hemisphere dysfunction. Whilst beyond the scope of this review, the benefits of multichannel VEPs in the investigation of intracranial pathway abnormalities are encouraged and are discussed preservation of peripheral RGC function. Optic neuritis: The PERG shows normal P50 components but mildly reduced N95 components to both field sizes. The PR-VEP is atypically delayed but with preserved amplitude, alongside the F-VEP which is preserved. The PhNR is markedly reduced with normal a- and b-waves. Overall, this indicates some optic nerve dysfunction with some level of retrograde degeneration to the RGCs centrally, with marked peripheral RGC dysfunction. Macular dystrophy: The PERG P50 to a $30^{\circ}$ field is well defined, but that to a $15^{\circ}$ field is absent indicating marked macular dysfunction localised to the central $15^{\circ}$ field. The PR-VEP to $50^{\prime}$ check widths is of normal peak-time but borderline amplitude, with loss of the PR-VEP to small check widths. The F-VEP is of appropriate amplitude, with the PhNR within normal limits also. Overall, this indicates localised macular dysfunction affecting the $15^{\circ}$ field with preservation of the surrounding $15-30^{\circ}$ field. The preserved N95:P50 ratio and PhNR indicating normal RGC and optic nerve function. elsewhere within this issue, particularly of benefits in patients unable to undertake visual field examination.

Compression of the anterior visual pathway can be from a variety of causes, for example optic pathway glioma, craniopharyngioma, haemangiomas, pituitary adenoma, meningiomas or cerebral aneurysms near the visual pathway which may exert pressure on the optic nerve, some of which being infiltrative. The pattern of visual loss in anterior visual pathway lesions can affect both eyes, for example where the chiasm or tracts are affected, or one eye, for example where the globe or optic nerve are unilaterally affected. Several studies of VEPs have investigated the pattern and flash VEP in compressive lesions of the anterior visual pathways $[106,107$, 110-113], including 

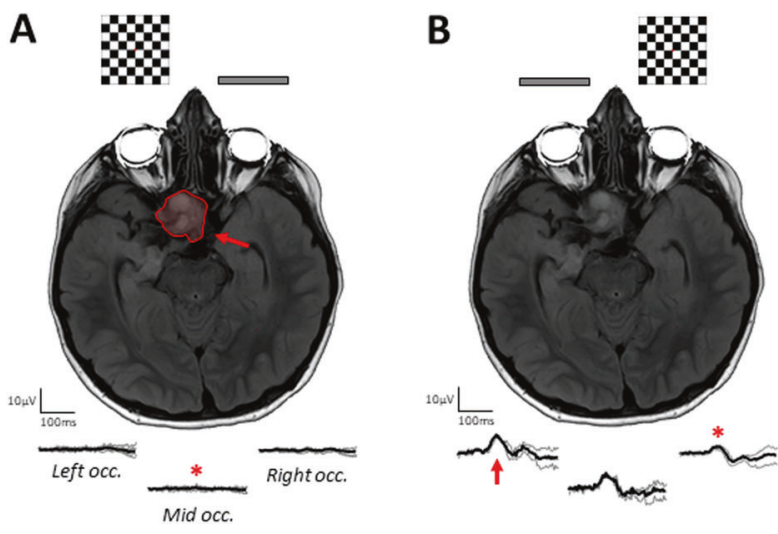

Fig. 4 An illustrative case of compressive/infiltrative optic neuropathy in an 8 year old male patient with an optic pathway glioma involving the left optic nerve, chiasm and left optic tract (red arrow and outline). From the left, the MRI is shown and checkerboard stimuli demonstrating the presentation of the pattern stimulus respectively. The occipital VEP responses are shown at the bottom from the left, middle and right occiput respectively. A No reproducible PR-VEP is evident to left eye stimulation. B A reproducible PR-VEP is seen at the occiput to full-field PR-VEP stimulation of the right eye,

intraoperatively during surgical decompression [114]. These studies overall demonstrate that in compressive lesions of the anterior visual pathway the PR-VEP will become delayed, with variable degrees of amplitude loss, alongside morphology changes in the waveform. Interestingly it has also been demonstrated that VEPs can be abnormal even in the absence of a measurable visual field defect or reduction in high contrast visual acuity [111, 115-117]. Furthermore, particularly for optic pathway gliomas, VEPs have high sensitivity for detecting functional abnormality [118, 119], which is particularly advantageous in children for whom behavioural perimetric testing is unreliable $[120,121]$ although their ability to monitor progression is less certain. Perhaps most relevant in compressive lesions are the aforementioned transoccipital distribution of VEPs, ideally using half-field stimuli, which is particularly important in the investigation of delayed VEPs, as chiasmal or retrochiasmal lesions are much less frequently observed in demyelinating disease [98, 122] (Fig. 4). The mfVEP has also been studied in compressive anterior pathway lesions and tends to show similar changes to behavioural perimetric findings [123-126], but are of debatable clinical use over existing techniques due to their demanding technical requirements. Interestingly, the mfPERG has been demonstrated to show good correlation between amplitude and degree of VF defect in chiasmatic lesions [49, 50].

The PERG in compressive lesions predominantly shows reduction in the N95 component, although P50 amplitude reduction is seen where PR-VEPs are severely abnormal [79]. It has also been demonstrated that PERG abnormalities are associated with worse visual outcome post-surgically, as this reflects retrograde degeneration to the RGCs
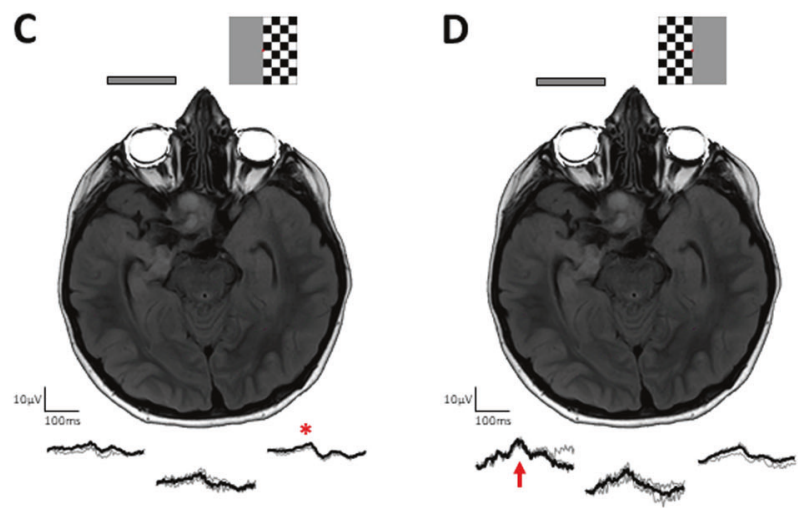

however this is best defined over the left- and mid-occiput (red arrow) and attenuated over the right occiput (red asterisk). C Selective right half-field stimulation for the right eye demonstrates a reduced ipsilateral positivity expected (red asterisk). D Selective left half-field stimulation of the left eye demonstrates a preserved positivity (red arrow) similar to the full-field PR-VEP. Overall, PR-VEPs indicate profound macular pathway dysfunction affecting the LE and RE crossing fibres, but relatively preserved RE non-crossing fibres subserving the left half-field.

rather than any transient or reversible visual loss [79, 127, 128]. The PhNR in compressive optic neuropathy was demonstrated in five patients where amplitude was found to be reduced similar to patients with AION [129]. Following this finding, a later study by Moon et al. [130] demonstrated in 18 patients with chiasmal compression that $\mathrm{PhNR}$ was reduced relative to controls but importantly that this correlated significantly with post-operative visual field sensitivity recovery, suggesting the PhNR has prognostic value. Moon et al. [131] also showed in their accompanying work that the PhNR reduction persisted and had some improvement by six months, albeit this did not reach statistical significance. The prognostic value of the PhNR against the PERG in predicting the recovery of visual function following treatment of compressive optic neuropathy is yet to be determined. The PhNR has also been reported to be significantly reduced in childhood optic pathway glioma, and demonstrated a strong relationship with the mean RNFL thickness [132]. These authors also remarked how the PhNR recording was achievable in all children, whereas OCT examination was not possible in one-third of their cohort due to motion artefacts or scan quality, which is a valuable concern for paediatric practice.

Endocrinological disorders of the thyroid, such as in Graves disease, can give rise to thyroid-associated orbitopathy (TAO). In TAO, the retro-orbital space can become reduced due to muscular fibrosis, inflammation and fat accumulation which causes compression of the optic nerve, known as dysthyroid optic neuropathy (DON). In DON, the PERG can show early optic nerve involvement [133, 134] with N95 amplitude loss, although P50 reductions have also been reported [134, 135]. VEP findings tend show latency 
delay and variable degree of amplitude reduction [134, 136140], which can improve following surgical decompression [141]. Further to TAO, PR-VEPs have also been studied in autosomal recessive osteopetrosis, where latency delay can be seen [14]. In particular, PR-VEPs recorded to higher spatial frequencies (i.e. small check widths) in a range of compressive optic neuropathies may be more sensitive in detection of early changes associated with compression of the anterior visual pathway [14, 113, 120, 139].

PR-VEP amplitude reduction is a hallmark finding in cases of toxic optic neuropathy [142-145] and VEP responses can be subnormal even after visual acuity recovery suggesting persistence of subclinical changes $[146,147]$. However, VEPs performed in isolation cannot localise the functional deficit to the level of the optic nerve and must be performed in conjunction with pattern and flash ERG to confirm RGC and/or optic nerve functional deficit with a normally functioning outer retina $[148,149]$.

VEP waveform delay and amplitude reduction is not a surprising finding in patients with traumatic optic neuropathies. However, interestingly there are multiple reports suggesting that VEP measurements obtained soon after traumatic optic nerve injury not only correlates with the patient's visual acuity but may also have some predictive value towards visual prognosis, more so in patients unable to respond to subjective visual testing at the time of injury [150-155]. The value of the PERG and PhNR in assessing RGC function in traumatic optic neuropathy has seldom been explored.

VEP, PERG and PhNR have been employed extensively in studies of Glaucoma in the clinical setting for evaluation of RGC dysfunction and death and this information is covered elsewhere in this issue.

\section{Vascular causes of optic nerve and RGC dysfunction}

Metabolic and vascular abnormalities secondary to hyperglycaemia contribute to diabetic neuropathies including diabetic retinopathy [156]. PR-VEP changes manifest as a combination of response delay and amplitude reduction, overall with response delays preceding amplitude delays in diabetics with either mild or no retinopathy [157-163]. PRVEP changes are typically accompanied by brainstem auditory and somatosensory evoked potential abnormalities indicating that there may be a more diffuse deficit of the central sensory systems [164-167]. The PR-VEP abnormalities in diabetics generally tend to be accompanied by PERG changes, suggesting that the VEP changes to a large extent are likely a reflection of RGC dysfunction [161, 168, 169] and PERG changes are graded with the severity of diabetic retinopathy with demonstrable amplitude reduction, sometimes with this tendency seen also in patients with no visual symptoms or clinical signs of retinopathy $[160,168,170,171]$ and with interaction of factors like age of onset and duration of diabetes [170]. The b-wave of the dark-adapted flash ERG is affected with increase in duration and severity of diabetic retinopathy [160] thus warranting careful evaluation of photoreceptor and bipolar cell function with the flash ERG which also allows testing RGC function with the appropriate stimulus conditions. There is general consensus in the published literature that the PhNR amplitude is reduced in diabetic eyes and that there is a graded effect on the PhNR amplitude with increasing disease severity, with b-wave reduction accompanying PhNR changes in severe stages [171-175]. However, there is some disagreement on how early in the disease process the PhNR amplitude changes manifest [171, 173-175]. While some studies demonstrate a significant reduction or a tendency towards reduction of PhNR amplitude in eyes with no retinopathy $[171,173,175]$, others report no change [172]. This discrepancy can be attributed to differences between these studies in the ERG stimulus characteristics, recording techniques, patient demographics and clinical grading systems of retinopathy severity. There is also some indication that the STR waveform is delayed with reduced amplitude in diabetic eyes [176].

Electrodiagnostic evaluation of neuronal function in retinal vascular occlusions is typically performed with the flash ERG as compromised retinal circulation affects retinal bipolar and ganglion cell function. The PR-VEP and PERG are not routinely employed in the clinical evaluation of retinal circulatory abnormalities as they are less informative in these conditions. Central Retinal Artery Occlusion, Central Retinal Vein Occlusion and Branch Retinal Vein Occlusion all reduce the amplitude of the b-wave and the PhNR [130, 177-188]. The PhNR is usually more reduced than the $b$-wave, implying greater dependence of more inner retinal neurones on retinal circulation [130, 177-183, 185188]. The recovery of retinal function, whether spontaneously or as a result of treatment, is more robust with improvement b-wave in the initial phase and the PhNR recovering over longer time-period [130, 184, 186, 187]. The magnitude of PhNR amplitude reduction before treatment has been suggested to be a better predictor of visual prognosis than the b-wave [130, 179].

The non-perfusion or hypoperfusion of the optic nerve itself can result in an ischaemic optic neuropathy. Ischemic optic neuropathy (ION) typically comprises two major types; anterior (AION) which affects the optic nerve head, and posterior (PION) which affects the portion of the nerve posterior to the nerve head. These can be further characterised into those caused by an arteritic process or nonarteritic process (i.e. AAION or NAION respectively) 
[189]. The management of ION and their subtypes can differ, as can their visual prognosis [190].

The VEP abnormalities in ischaemic optic neuropathy were first formally introduced by Wilson [191] who demonstrated the amplitude reduction of the PR-VEP, with small or no changes in latency seen. Other studies are in general agreement with Wilson's amplitude findings, but some studies report varying degrees of latency abnormality, suggesting commensurate conduction delay is not an exclusion to VEP diagnosis of ION [192-195]. Further, utilising a small check width PR-VEP was found to have higher sensitivity in the detection of optic nerve dysfunction [194]. There has been conflicting evidence to whether latency delay is a truly a feature of ION. Some of this may arise around the heterogeneous cohorts recruited within these early studies or consideration for the timing of PR-VEPs after the acute event. For example, it has since been noted that within the acute phase of ION that latency can be more affected [196]. Furthermore, it is unknown whether PR-VEP morphology changes or field defects were accounted for, as a central scotoma or altitudinal field defects can reduce the macular derived P100 and enhance the paramacular components of the VEP (i.e. producing a bifid or ' $p-n-p$ ' waveform). This can mistakenly be construed as an atypically early or delayed P100 as demonstrated by Thompson [197], therefore half-field PR-VEPs are essential to elaborate on the origins of the components observed, as are PR-VEPs to a range of check widths [198]. Overall, a fair conclusion now is that ION predominantly affects PR-VEP amplitude, but latency can in some circumstances be affected, but is typically less marked than that observed in optic neuritis [194, 197-202]. The flash VEP is typically lower amplitude with latency changes [202].

While the PERG N95 amplitude reduction is a common clinical feature in ischemic optic atrophy, this has been studied less frequently [194, 195, 201, 202]. Interestingly it was proposed that in the acute phase of visual loss, if the PERG is recorded within 8-35 days from onset this shows rapid loss of the N95 component in AION, whereas in optic neuritis this not as frequently seen [195, 203], but this finding has not been validated. PERG abnormalities of the P50 component have also been reported, which may suggest some incipient dysfunction upstream to the RGCs at the macular photoreceptors or bipolar cells, although this has not widely observed [195].

Rangaswamy et al. [129] demonstrated in 17 patients with NAION that the PhNR amplitude is reduced and its decrease correlated to the reduction in visual field sensitivity. Including a control group, these authors demonstrated in their Receiver Operating Curve that the PhNR has $96 \%$ diagnostic accuracy for AION. Interestingly it was also found that the PhNR was reduced in some degree in the asymptomatic eyes, suggesting there may be subtle signs of global RGC dysfunction before clinical signs of AION may appear. Further studies of the PhNR have included heterogenous cohorts of optic nerve disease, some including ischemic optic neuropathies, with variable degree of PhNR change [204, 205]. Beyond the PhNR, it has been shown that impairment of OPs can also occur in AION [206], which was observed particularly in OP2 and OP3 in a later study [202], presumably secondary to ischemic changes at the inner retina. The mfVEP can provide further information regarding optic nerve integrity, particularly as they demonstrate a close relationship between visual field loss and topographic mfVEP amplitude reduction, although this may overlap with other optic neuropathies [207, 208].

\section{Optic neuritis and demyelinating disease}

Optic neuritis and other inflammatory disorders of the optic nerve can give rise to significant visual impairment, warranting early identification of aetiology which can facilitate diagnosis, prognosis and management. The use of electrophysiology in optic neuritis has been extensively studied in the context of demyelinating disorders. As the PR-VEP assesses the integrity of the visual pathway from the macula to striate cortex, it can be used in the detection of optic nerve and intracranial pathway abnormalities but can lack specificity for the underlying disease. For example, whilst optic neuritis is most historically associated with Multiple Sclerosis (MS), its presentation, history or PR-VEP changes can have wide differential diagnosis including infectious (i.e. Lyme disease, Herpes Zoster, toxoplasmosis), vascular (i.e. ION), toxic/nutritional (i.e. B12 deficiency, ethambutol, or tobacco-alcohol toxicity), Compressive (i.e. intracranial tumours), disseminated neurological disorder (i.e. Adrenoleukodystrophy, Neuromyelitis Optica Spectrum (NMO) disorder), hereditary optic neuropathies (i.e. LHON or ADOA) or systemic disease (i.e. Systemic Lupis Erythematosus, Sjögrens syndrome or Sarcoid) [209]. The type of PVEP abnormality may in some instances characterise some of these pathologies, but often demands the additional use of a PERG to further aid diagnosis.

Optic Neuritis can often be the first presentation of disease in MS, occurring in 13-15\% of patients [210]. Furthermore, many patients with MS can show optic nerve or PR-VEP abnormalities despite the absence of visual symptoms or MRI abnormalities of the orbit [211-213]. The early works pioneering the clinical utility of the PR-VEP in optic neuritis came from Halliday et al. who demonstrated an increased latency in the PR-VEP as characteristic for conduction delay associated with demyelination [211, 214]. The PR-VEP in acute phase of optic neuritis is often 
unrecordable, significantly attenuated or delayed, likely subsequent upon conduction block of the axonal volley [215]. After the acute phase, amplitude often improves but the delay most commonly persists despite the resolution of visual acuity or field defects [211]. Over 6-36 months the latency can slowly decrease presumably concordant with remyelination, sodium channel reorganisation or cortical receptive field plasticity [216-218], but still remains abnormal in the majority of cases [219]. Amplitude recovery is more quickly and closely related with the clinical improvement in visual acuity [220]. It is important to note that in children normalisation of the PR-VEP is more common than in adults, often occurring within 12 months [221].

The abnormality of a PVEP should always be investigated with a PERG whenever possible to identify the locus of visual system dysfunction, as a PVEP abnormality may be consequent upon either a maculopathy or RGC dysfunction (Fig. 3). Holder [222] demonstrated that in 199 eyes with abnormal PVEPs from optic nerve demyelination, $39.2 \%$ of these demonstrated abnormality of the PERG, the majority of which affecting the N95 component. It was later demonstrated by Holder [79] in a large series that the reduction of the N95:P50 ratio of the PERG is closely related to a greater severity of conduction delay in the PRVEP. It may take up to 6 weeks for a PERG abnormality to appear after acute optic neuritis. This reflects the time taken for retrograde degeneration to occur to RGC axons, which then predominantly affects the N95 component. It has been demonstrated that N95 component loss following optic neuritis is associated with a worse visual prognosis, and correlates with structural measures of macular ganglion cell complex volume (GCCV) and nerve fibre layer thickness [223-226]. In cases of severe N95 reduction, the P50 component may also reduce in amplitude and shorten in peak-time. In the acute phase, the P50 component can also be reduced reflecting some central retinal dysfunction, but this observation typically resolves within 4 weeks [79, 227]. As the PERG N95 loss in optic neuritis typically occurs after the acute phase of vision loss, a reduced PERG N95 during acute presentation suggests other primary RGC disease such as LHOA or other optic nerve pathology.

There are only a few studies at the time of writing that have investigated optic neuritis and demyelinating disease using the PhNR. So far, these suggest that the PhNR may be useful in the delineation between structural and functional visual measurements, where functional change can precede changes in RNFL thickness. Wang et al. [228] found that the PhNR in MS has reduced amplitude across an entire stimulus-intensity range tested, interestingly in eyes with and without a history of optic neuritis. Furthermore, in those with a history of optic neuritis, a close correlation can be observed to visual field changes and RNFL thickness. In particular, the most marked change observed was in patients with a history of optic neuritis longer than 6 months prior to testing, suggesting the PhNR is sensitive in detecting the retrograde degeneration of RGC cell axons. Whilst there may be some concern regarding the PhNR discriminatory ability against visual fields the only study to address this utilised reference data from two different populations and hence the verdict is inconclusive [228]. The PhNR during the acute phase of optic neuritis can also be abnormal, possibly secondary to neuronal swelling, inflammation or glial cell disruption which contribute to the PhNR [29, 92]. It has also been demonstrated using the focal macula ERGs, that the a- and b-waves were significantly reduced in the central $15^{\circ}$ field alongside the PhNR reduction, which may persist following visual improvement [204]. It is interesting to note that the PhNR has shown earlier changes than structural measurements of RNFL thinning in severe inflammatory conditions causing optic atrophy, where the PhNR becomes abnormal after only 1 month whereas RNFL changes can take up to 3 months to manifest [229]. An illustration of a patient with optic neuritis is presented in Fig. 3 which shows the PERG, PR-VEP, F-VEP and PhNR waveform alterations.

The mfVEP can assess the functional regions of the optic nerve and therefore may be of benefit in some cases of optic neuritis. For example, in mild forms of optic neuritis, where topographically only a small segment of nerve axons are affected (i.e. causing a small scotoma or peripheral field defect), the conventional VEP may mask an underlying defect as it is produced from both normal and abnormally functioning axons, whereas the mfVEP may detect this focal loss [230, 231]. However, the technical demands of a mfVEP and its accessibility have limited its widespread use to date.

\section{Papilloedema and raised intracranial pressure}

Raised intracranial pressure (rICP) and papilloedema can cause significant visual impairment if left untreated. The mechanism of visual loss is likely a result of RGC dysfunction secondary to mechanical or compressive effects on the optic nerve which disrupt axoplasmic flow resulting in nerve fibre swelling, clinically known as papilloedema [232]. As the effects of rICP impacts the RGCs, optic nerve and visual pathway, electrophysiology as an objective functional measure of these neuronal components offers advantages over existing methods such as visual acuity or papilloedema grading, which can be insensitive to change in rICP [233]. In particular, differentiation of optic disc oedema from rICP and from optic neuropathies, which is crucial for ongoing management, may be achieved through electrophysiology. 


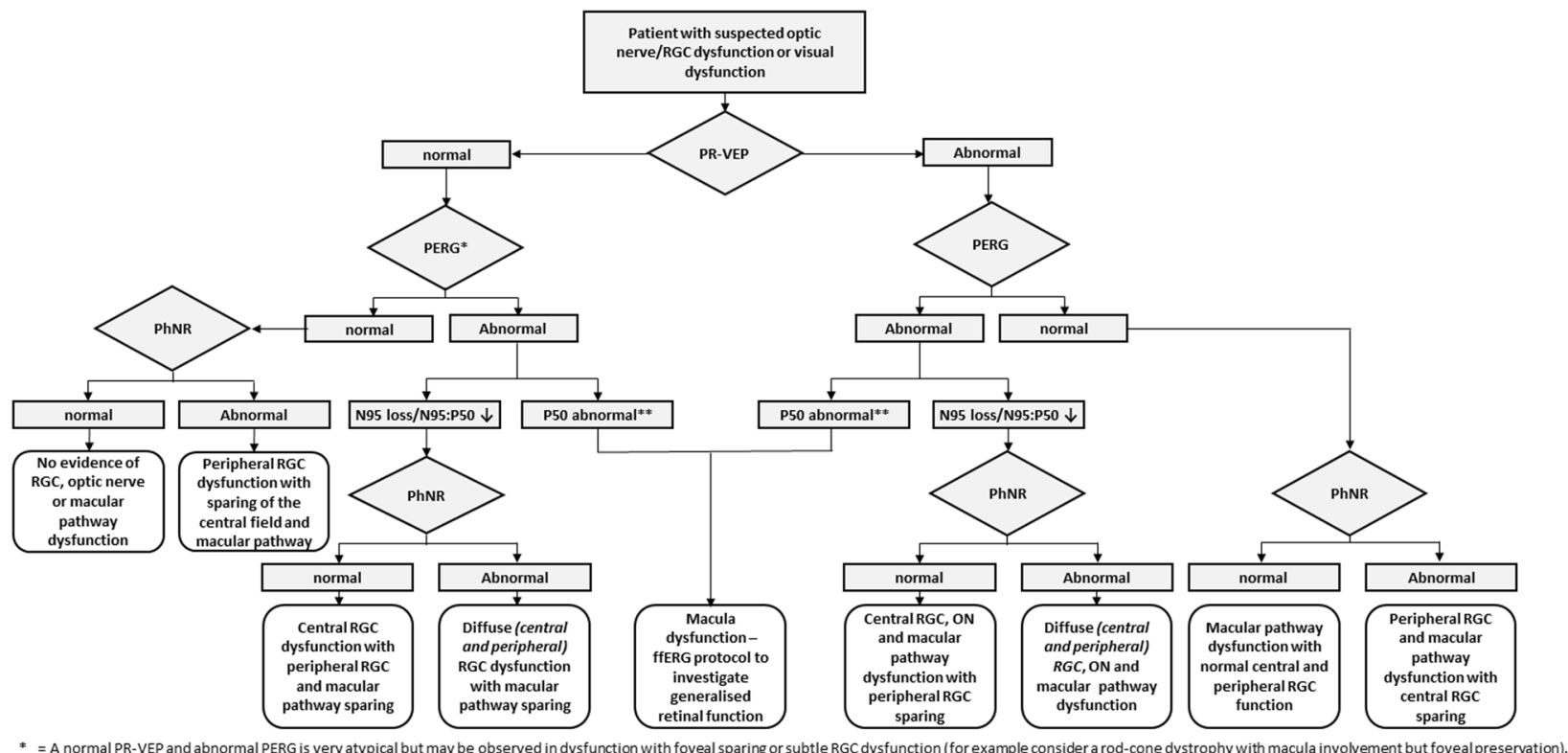

$\begin{array}{ll}*= \\ * *\end{array}=$ This excludes an abnormal P50 amplitude in the acute phase of opticnerve/RGC disease or its reduction in context of severe N95 loss

Fig. 5 Proposed diagnostic algorithm for the use of the pattern electroretinogram (PERG), pattern visual evoked potential (PVEP) and photopic negative response (PhNR) in clinical practice. The reader can follow the different scenarios whereby the PVEP, PERG or PhNR may be normal or abnormal, to ascertain what clinical conclusions may be drawn from these findings. It is stressed by the

Early publications reported high correlation between N2 latency of the F-VEP and invasively recorded ICP, including reports that the F-VEP aided in the detection of posterior visual pathway abnormalities associated with paediatric rICP, such as 'stretching' the optic radiations or chiasmal dysfunction from ventricular enlargement or alteration [233-236]. However, the high inter-subject variability of the F-VEP has precluded any reliable absolute amplitude or latency measurements to indicate rICP and therefore its use in rICP is limited. Conversely, the PERG and PR-VEP demonstrate relatively low intra- and intersubject variability. Early studies of PR-VEPs in rICP demonstrated P100 latency prolongation between patients with Idiopathic Intracranial Hypertension (IIH) and controls, with modest correlation with ICP. These PR-VEP alterations in normalised when papilloedema and blind-spot areas resolved [237, 238]. However, PR-VEPs in IIH have overall demonstrated variable sensitivity and clinical utility [239-241]. Nevertheless, an abnormal PR-VEP at baseline does predict worse visual outcome and shares a close relationship with visual field abnormalities [241, 242]. Other studies have demonstrated a high prevalence of PRVEP abnormality in paediatric craniosynostosis [243], including the use of serial PR-VEPs in longitudinal monitoring of rICP, some demonstrating a $71 \%$ sensitivity and 100\% specificity for rICP [244-246]. These were detected through longitudinal study of PR-VEPs recorded to a range of spatial frequencies, which improves the sensitivity of authors, that this algorithm should be interpreted in the clinical context, and not all diseases or patterns of optic nerve or retinal ganglion cell dysfunction conform to these patterns. In these circumstances, detailed clinical examination, history taking, imaging, genetic or other laboratory testing may be necessary to aid diagnosis.

detecting rICP in craniosynostosis and IIH [247]. The variable sensitivity of PVEPs in these conditions likely reflects a variance of methodological approaches, such as only performing a PR-VEP to one spatial frequency or use of a small stimulus field size. The challenge with PR-VEPs as a marker of optic nerve and RGC dysfunction in IIH, is the site of dysfunction in IIH as a 'pure' form of rICP (i.e. one where intracranial compliance is mostly unaffected, relative to Craniosynostosis or Hydrocephalus) is predominantly at the RGCs, therefore the VEP as a measure of the entire visual pathway may conceal early changes, such as from mechanisms of post-retinal contrast adaptation [248, 249].

The PERG and PhNR hold promise in the objective measurement of visual function in patients with papilloedema and/or rICP. This can provide complementary topographic information of functioning RGC populations, which is of interest in rICP as the central visual field is often only affected late in the disease course [233]. It has been demonstrated that the steady state PERG can be abnormal in $77.7 \%$ of patients with IIH, particularly to higher spatial frequencies as observed in the PVEP [247]. The PERG N95 has a close relationship with VF sensitivity and OCT GCCV and RNFL thickness [250]. More recently, the PhNR was studied in IIH where they found $60 \%$ of patients to have reduced amplitude that correlated significantly with the SAP-MD and macula GCCV volume [251]. For one case in this cohort, aggressive ICP reducing treatment normalised 
the PhNR, improved the papilloedema grading, but did not alter the SAP-MD. This demonstrates some distinction from optic neuritis where the PhNR often remains abnormal despite resolution of visual symptoms. A later study compared the focal and full-field PhNR and PERG in patients with $\mathrm{IIH}$, which corroborated their existing findings of an abnormal PhNR in IIH affecting the full-field more than focal PhNR, suggesting the topographic peripheral field abnormalities seen in IIH are concordant with the PhNR findings [252]. However, the comparative normality of the focal-PhNR compared to the abnormal PERG in the same patients are curious, perhaps reflecting differences between each stimulus modality and their relative origins. They did, however, find a relatively low sensitivity of the PERG in IIH $(45.5 \%)$, perhaps reflecting differences between the transient and steady-state PERG and the influence of different spatial frequencies. These findings overall suggest that the PhNR and PERG are useful indicators of optic nerve and RGC function in rICP, but to date have not been directly associated with ICP measurements as a surrogate marker.

\section{Visual electrophysiology in practice}

In this review we have studied a variety of techniques, such as the PERG, VEP and PhNR, in conditions affecting the optic nerve and RGCs. The authors encourage those undertaking electrophysiological testing to meet the minimum standards for recording and exceed these where possible, to further characterise the site of dysfunction. In the clinical interpretation of data, one may wish to interpret findings of PERGs, VEPs and PhNR together to aid decision making and analysis. As such, we propose a simple decision flow-chart for the interested reader in how to interpret these tests together, to aid clinical interpretation of electrophysiological tests (Fig. 5). It is important to consider the clinical and technical factors which may influence findings, such as test time after an acute event, comorbidities or reduced compliance. The authors encourage recording a PERG and PR-VEP simultaneously, where possible, to maximise the diagnostic value of electrophysiological tests alongside factoring in these variables.

\section{Conclusion}

Visual electrophysiology is a key diagnostic tool in the assessment of conditions affecting RGCs and the optic nerve. In this review we have discussed the role of the PERG, VEP, PhNR in characterising visual function in RGC and optic nerve disease. The benefits of electrophysiology are to provide functional data of the visual system to complement structural data and the clinical examination. At the advent of the genomic era and beginning of new exciting therapies for optic nerve disease, functional measurements will be essential for measuring safety, efficacy and outcome. Furthermore, the objective nature of electrophysiology testing means information about the visual system can be gained from patients unable to complete subjective tests. The ability to assess RGC and optic nerve function quantitatively and through different but complementary tests builds a diagnostic platform for phenotyping of disease, which can aid in clinical decision making.

Author contributions Both OM and SV were responsible for designing the review strategy, conducting the search, screening of eligible studies, extraction and analysis of data, interpretation and collation of findings. OM and SV were responsible for writing of the study paper and generation of figures. Both authors approve to the final version of the paper.

\section{Compliance with ethical standards}

Conflict of interest The authors declare no competing interests.

Publisher's note Springer Nature remains neutral with regard to jurisdictional claims in published maps and institutional affiliations.

Open Access This article is licensed under a Creative Commons Attribution 4.0 International License, which permits use, sharing, adaptation, distribution and reproduction in any medium or format, as long as you give appropriate credit to the original author(s) and the source, provide a link to the Creative Commons license, and indicate if changes were made. The images or other third party material in this article are included in the article's Creative Commons license, unless indicated otherwise in a credit line to the material. If material is not included in the article's Creative Commons license and your intended use is not permitted by statutory regulation or exceeds the permitted use, you will need to obtain permission directly from the copyright holder. To view a copy of this license, visit http://creativecommons. org/licenses/by/4.0/.

\section{References}

1. Thompson DA, Fritsch DM, Hardy SE. The changing shape of the ISCEV standard pattern onset VEP. Doc Ophthalmol. 2017;135:69-76.

2. Odom JV, Bach M, Brigell M, Holder GE, McCulloch DL, Mizota A, et al. ISCEV standard for clinical visual evoked potentials: (2016 update). Doc Ophthal. 2016;133:1-9.

3. Carroll WM, Halliday AM, Kriss A. Improvements in the accuracy of pattern visual evoked potentials in the diagnosis of visual pathway disease. Neuro-Ophthalmol. 1982;2:237-53.

4. Skuse NF, Burke D, Mckeon B. Reproducibility of the visual evoked potential using a light-emitting diode stimulator. J Neurol Neurosurg Psychiatry. 1984;47:623-9.

5. Sarnthein J, Andersson M, Zimmermann MB, Zumsteg D. High test-retest reliability of checkerboard reversal visual evoked potentials (VEP) over 8 months. Clin Neurophysiol. 2009;120:1835-40. 
6. Mellow TB, Liasis A, Lyons R, Thompson DA. The reproducibility of binocular pattern reversal visual evoked potentials: a single subject design. Doc Ophthal. 2011;122:133-9.

7. Andersson L, Sjölund J, Nilsson J. Flash visual evoked potentials are unreliable as markers of ICP due to high variability in normal subjects. Acta Neurochir. 2012;154:121-7.

8. Meredith JT, Celesia GG. Pattern-reversal visual evoked potentials and retinal eccentricity. Electroencephalogr Clin Neurophysiol. 1982;53:243-53.

9. Yiannikas C, Walsh JC. The variation of the pattern shift visual evoked response with the size of the stimulus field. Electroencephalogr Clin Neurophysiol. 1983;55:427-35.

10. Celesia GG. Evoked potential techniques in the evaluation of visual function. J Clin Neurophysiol. 1984;1:55-76.

11. Oishi M, Yamada T, Dickins SS, Kimura J. Visual evoked potentials by different check sizes in patients with multiple sclerosis. Neurology. 1985;35:1461-5.

12. Hughes JR, Stone JL, Fino JJ, Hart LA. Usefulness of different stimuli in visual evoked potentials. Neurology. 1987;37:656-62.

13. Novak GP, Wiznitzer M, Kurtzberg D, Giesser BS, Vaughan HG. Utility of visual evoked potentials using hemifield stimulation and several check sizes in the evaluation of suspected multiple sclerosis. Electroencephalogr Clin Neurophysiol. 1988;71:1-9.

14. Thompson DA, Kriss A, Taylor D, Russell-Eggitt I, Hodgkins P, Morgan G, et al. Early VEP and ERG evidence of visual dysfunction in autosomal recessive osteopetrosis. Neuropediatrics. 1998;29:137-44.

15. Thurtell MJ, Bala E, Yaniglos SS, Rucker JC, Peachey NS, Leigh RJ. Evaluation of optic neuropathy in multiple sclerosis using low-contrast visual evoked potentials. Neurology. 2009;73:1849-57.

16. Sartucci F, Murri L, Orsini C, Porciatti V. Equiluminant redgreen and blue-yellow VEPs in multiple sclerosis. J Clin Neurophysiol. 2001;18:583-91.

17. Tekavčič Pompe M, Perovšek D, Šuštar M. Chromatic visual evoked potentials indicate early dysfunction of color processing in young patients with demyelinating disease. Doc Ophthal. 2020;141:157-68.

18. Porciatti V, Sartucci F. Retinal and cortical evoked responses to chromatic contrast stimuli. Specific losses in both eyes of patients with multiple sclerosis and unilateral optic neuritis. Brain. 1996;119:723-40.

19. Majander A, Robson AG, João C, Holder GE, Chinnery PF, Moore AT, et al. The pattern of retinal ganglion cell dysfunction in Leber hereditary optic neuropathy. Mitochondrion. 2017;36:138-49.

20. Fuest M, Kieckhoefel J, Mazinani B, Kuerten D, Koutsonas A, Koch E, et al. Blue-yellow and standard pattern visual evoked potentials in phakic and pseudophakic glaucoma patients and controls. Graefes Arch Clin Exp Ophthalmol. 2015;253:2255-61.

21. Sartucci F, Porciatti V. Visual-evoked potentials to onset of chromatic red-green and blue-yellow gratings in Parkinson's disease never treated with L-dopa. J Clin Neurophysiol. 2006;23:431-5.

22. Risuenho BBO, Miquilini L, Eliza EM, Silveira LCL, Souza GS. Cortical responses elicited by luminance and compound stimuli modulated by pseudo-random sequences: comparison between normal trichromats and congenital red-green color blinds. Front Psychol. 2015;6:53.

23. Crognale MA, Page JW, Fuhrel A. Aging of the chromatic onset visual evoked potential. Optom Vis Sci. 2001;78:442-6.

24. Luo X, Frishman LJ. Retinal pathway origins of the pattern electroretinogram (PERG). Investig Ophthalmol Vis Sci. 2011;52:8571-84.
25. Holder GE. Pattern electroretinography (PERG) and an integrated approach to visual pathway diagnosis. Prog Retin Eye Res. 2001;20:531-61.

26. Kakisu Y, Mizota A, Adachi E. Clinical application of the pattern electroretinogram with lid skin electrode. Doc Ophthal. 1986;63:187-94.

27. Lenassi E, Robson AG, Hawlina M, Holder GE. The value of two-field pattern electroretinogram in routine clinical electrophysiologic practice. Retina. 2012;32:588-99.

28. Bach M, Brigell MG, Hawlina M, Holder GE, Johnson MA, McCulloch DL, et al. ISCEV standard for clinical pattern electroretinography (PERG): 2012 update. Doc Ophthal. 2013;126:1-7.

29. Viswanathan S, Frishman LJ, Robson JG, Harwerth RS, Smith EL. The photopic negative response of the macaque electroretinogram: reduction by experimental glaucoma. Investig Ophthalmol Vis Sci. 1999;40:1124-36.

30. McCulloch DL, Marmor MF, Brigell MG, Hamilton R, Holder GE, Tzekov R, et al. ISCEV Standard for full-field clinical electroretinography (2015 update). Doc Ophthal. 2015;130:1-12.

31. Rangaswamy NV, Shirato S, Kaneko M, Digby BI, Robson JG, Frishman LJ. Effects of spectral characteristics of ganzfeld stimuli on the photopic negative response (PhNR) of the ERG. Investig Ophthalmol Vis Sci. 2007;48:4818-28.

32. Sustar M, Cvenkel B, Brecelj J. The effect of broadband and monochromatic stimuli on the photopic negative response of the electroretinogram in normal subjects and in open-angle glaucoma patients. Doc Ophthal. 2009;118:167-77.

33. Frishman L, Sustar M, Kremers J, McAnany JJ, Sarossy M, Tzekov R, et al. ISCEV extended protocol for the photopic negative response $(\mathrm{PhNR})$ of the full-field electroretinogram. Doc Ophthal. 2018;136:207-11.

34. Binns AM, Mortlock KE, North R V. The relationship between stimulus intensity and response amplitude for the photopic negative response of the flash electroretinogram. Doc Ophthal. 2011;122:39-52.

35. Tang J, Edwards T, Crowston JG, Sarossy M. The Test-Retest Reliability of the Photopic Negative Response (PhNR). Transl Vis Sci Technol. 2014;3:1.

36. Joshi NR, Ly E, Viswanathan S. Intensity response function of the photopic negative response (PhNR): effect of age and test-retest reliability. Doc Ophthal. 2017;135:1-16.

37. Sutter EE, Tran D. The field topography of ERG components in man - I. The photopic luminance response. Vis Res. 1992;32:433-46.

38. Hoffmann MB, Bach M, Kondo M, Li S, Walker S, Holopigian $\mathrm{K}$, et al. ISCEV standard for clinical multifocal electroretinography (mfERG) (2021 update). Doc Ophthal. 2021;142:5-16

39. Sutter EE, Bearse MA. The optic nerve head component of the human ERG. Vis Res. 2000;39:419-36.

40. van Alstine AW, Viswanathan S. Test-retest reliability of the multifocal photopic negative response. Doc Ophthal. 2017;134:25-36.

41. Al-Nosairy KO, Thieme H, Hoffmann MB. Diagnostic performance of multifocal photopic negative response, pattern electroretinogram and optical coherence tomography in glaucoma. Exp Eye Res. 2020;200:108242.

42. Baseler HA, Sutter EEM. M and P components of the VEP and their visual field distribution. Vis Res. 1997;37:675-90.

43. Baseler HA, Sutter EE, Klein SA, Carney T. The topography of visual evoked response properties across the visual field. Electroencephalogr Clin Neurophysiol. 1994;90:65-81.

44. Hoffmann MB, Flechner JJ. Slow pattern-reversal stimulation facilitates the assessment of retinal function with multifocal recordings. Clin Neurophysiol. 2008;119:409-17. 
45. Harrison WW, Viswanathan S, Malinovsky VE. Multifocal pattern electroretinogram: cellular origins and clinical implications. Optom Vis Sci. 2006;83:473-85.

46. Bach M, Cuno AK, Hoffmann MB. Retinal conduction speed analysis reveals different origins of the P50 and N95 components of the (multifocal) pattern electroretinogram. Exp Eye Res. 2018;169:48-53.

47. Klistorner AI, Graham SL, Martins A. Multifocal pattern electroretinogram does not demonstrate localised field defects in glaucoma. Doc Ophthal. 2000;100:155-66.

48. Stiefelmeyer S, Neubauer AS, Berninger T, Arden GB, Rudolph G. The multifocal pattern electroretinogram in glaucoma. Vis Res. 2004;44:103-12.

49. Monteiro MLR, Hokazono K, Cunha LP, Oyamada MK. Multifocal pattern electroretinography for the detection of neural loss in eyes with permanent temporal hemianopia or quadrantanopia from chiasmal compression. Br J Ophthalmol. 2012;96:104-9.

50. Monteiro MLR, Hokazono K, Cunha LP, Oyamada MK. Correlation between multifocal pattern electroretinography and Fourier-domain OCT in eyes with temporal hemianopia from chiasmal compression. Graefes Arch Clin Exp Ophthalmol. 2013;251:903-15.

51. Kurtenbach A, Kernstock C, Zrenner E, Langrová H. Electrophysiology and colour: a comparison of methods to evaluate inner retinal function. Doc Ophthal. 2015;131:159-67.

52. Kreuz AC, de Moraes CG, Hatanaka M, Oyamada MK, Monteiro MLR. Macular and Multifocal PERG and FD-OCT in Preperimetric and Hemifield Loss Glaucoma. J Glaucoma. 2018;27:121-32.

53. Sieving PA, Frishman LJ, Steinberg RH. Scotopic threshold response of proximal retina in cat. J Neurophysiol. 1986;56:1049-61.

54. Wakabayashi K, Gieser J, Sieving PA. Aspartate separation of the scotopic threshold response (STR) from the photoreceptor awave of the cat and monkey ERG. Investig Ophthalmol Vis Sci. 1988;29:1615-22.

55. Ogden TE. The oscillatory waves of the primate electroretinogram. Vis Res. 1973;13:1059-74.

56. Heynen H, Wachtmeister L, van Norren D. Origin of the oscillatory potentials in the primate retina. Vis Res. 1985;25:1365-73.

57. Wachtmeister L. Oscillatory potentials in the retina: what do they reveal. Prog Retin Eye Res. 1998;17:485-521.

58. Lenaers G, Hamel C, Delettre C, Amati-Bonneau P, Procaccio V, Bonneau D, et al. Dominant optic atrophy. Orphanet J Rare Dis. 2012;7:46.

59. Yu-Wai-Man P, Chinnery PF. Dominant optic atrophy: novel OPA1 mutations and revised prevalence estimates. Ophthalmology. 2013;120:1712-1712.e1.

60. Yu-Wai-Man P, Chinnery PF, Adam MP, Ardinger HH, Pagon RA, Wallace SE, et al. Leber Hereditary Optic Neuropathy. In: Adam MP, Ardinger HH, Pagon RA, Wallace SE, Bean LJH, Mirzaa G, et. al., editors. GeneReviews [Internet]. Seatle:University of Washington; 2000. p.1993-2021.

61. Chun BY, Rizzo JF. Dominant Optic Atrophy and Leber's Hereditary Optic Neuropathy: update on Clinical Features and Current Therapeutic Approaches. Semin Pediatr Neurol. 2017;24:129-34.

62. Sarzi E, Seveno M, Piro-Mégy C, Elzière L, Quilès M, Péquignot $\mathrm{M}$, et al. OPA1 gene therapy prevents retinal ganglion cell loss in a Dominant Optic Atrophy mouse model. Sci Rep. 2018;8:2468.

63. Harding GF, Crews SJ, Pitts SM. Psychophysical and visual evoked potential findings in hereditary optic atrophy. Trans Ophthalmol Soc U K. 1979;99:96-102.

64. Berninger TA, Jaeger W, Krastel H. Electrophysiology and colour perimetry in dominant infantile optic atrophy. $\mathrm{Br} \mathrm{J}$ Ophthalmol. 1991;75:49-52.
65. Holder GE, Votruba M, Carter AC, Bhattacharya SS, Fitzke FW, Moore AT. Electrophysiological findings in dominant optic atrophy (DOA) linking to the OPA1 locus on chromosome $3 \mathrm{q}$ 28-qter. Doc Ophthalmol. 1998-1999; 95:217-28.

66. Marra TR. The Clinical Significance of the Bifid or "W" Pattern Reversal Visual Evoked Potential. Clin Electroencephalogr. 1990;21:162-7.

67. Rousseff RT, Tzvetanov P, Rousseva MA. The bifid visual evoked potential - normal variant or a sign of demyelination? Clin Neurol Neurosurg. 2005;107:113-6.

68. Rinalduzzi S, Brusa A, Jones SJ. Variation of visual evoked potential delay to stimulation of central, nasal, and temporal regions of the macula in optic neuritis. J Neurol Neurosurg Psychiatry. 2001;70:28-35.

69. Miyata K, Nakamura M, Kondo M, Lin J, Ueno S, Miyake Y, et al. Reduction of oscillatory potentials and photopic negative response in patients with autosomal dominant optic atrophy with OPA1 mutations. Investig Ophthalmol Vis Sci. 2007;48:820-4.

70. Morny EKA, Margrain TH, Binns AM, Votruba M. Electrophysiological ON and OFF responses in autosomal dominant optic atrophy. Investig Ophthalmol Vis Sci. 2015;56:7629-37.

71. Yen MY, Wang AG, Wei YH. Leber's hereditary optic neuropathy: a multifactorial disease. Prog Retin Eye Res. 2006;25:381-96.

72. Meyerson C, van Stavern G, McClelland C. Leber hereditary optic neuropathy: current perspectives. Clin Ophthalmol. 2015;9:1165-76.

73. Nikoskelainen E, Hoyt WF. Ophthalmoscopic Findings in Leber's Hereditary Optic Neuropathy: II. The Fundus Findings in the Affected Family Members. Arch Ophthalmol. 1983;101:1059-68.

74. Sadun AA, Salomao SR, Berezovsky A, Sadun F, DeNegri AM, Quiros PA, et al. Subclinical carriers and conversions in leber hereditary optic neuropathy: a prospective psychophysical study. Trans Am Ophthalmol Soc. 2006;104:51-61.

75. Hwang TJ, Karanjia R, Moraes-Filho MN, Gale J, Tran JS, Chu ER, et al. Natural History of Conversion of Leber's Hereditary Optic Neuropathy: a Prospective Case Series. Ophthalmology. 2017;124:843-50.

76. Zhao X, Zhang Y, Lu L, Yang H. Therapeutic Effects of Idebenone on Leber Hereditary Optic Neuropathy. Curr Eye Res. 2020;45:1315-23.

77. Yang S, Ma SQI, Wan X, He H, Pei H, Zhao MJ, et al. Longterm outcomes of gene therapy for the treatment of Leber's hereditary optic neuropathy. EBioMedicine. 2016;10:258-68.

78. Zhang Y, Tian Z, Yuan J, Liu C, Liu HLI, Ma SQ, et al. The Progress of Gene Therapy for Leber's Optic Hereditary Neuropathy. Curr Gene Ther. 2017;17:320-6.

79. Holder GE. The pattern electroretinogram in anterior visual pathway dysfunction and its relationship to the pattern visual evoked potential: a personal clinical review of 743 eyes. Eye. 1997;11:924-34.

80. Ziccardi L, Sadun F, de Negri AM, Barboni P, Savini G, Borrelli $\mathrm{E}$, et al. Retinal function and neural conduction along the visual pathways in affected and unaffected carriers with Leber's hereditary optic neuropathy. Investig ophthalmol Vis Sci. 2013;54:6892-901.

81. Jarc-Vidmar M, Tajnik M, Brecelj J, Fakin A, Sustar M, Naji M, et al. Clinical and electrophysiology findings in Slovene patients with Leber hereditary optic neuropathy. Doc Ophthalmol. 2015;130:179-87.

82. Gualtieri M, Bandeira M, Hamer RD, Costa MF, Oliveira AGF, Moura ALA, et al. Psychophysical analysis of contrast processing segregated into magnocellular and parvocellular systems in asymptomatic carriers of 11778 Leber's hereditary optic neuropathy. Vis Neurosci. 2008;25:469-74. 
83. Karanjia R, Berezovsky A, Sacai PY, Cavascan NN, Liu HY, Nazarali S, et al. The Photopic Negative Response: an Objective Measure of Retinal Ganglion Cell Function in Patients With Leber's Hereditary Optic Neuropathy. Investig Ophthalmol Vis Sci. 2017;58:BIO300-6.

84. Botelho GIS, Salomão SR, Tengan CH, Karanjia R, Moura FV, Rocha DM, et al. Impaired Ganglion Cell Function Objectively Assessed by the Photopic Negative Response in Affected and Asymptomatic Members From Brazilian Families With Leber's Hereditary Optic Neuropathy. Front Neurol. 2021;11:628014.

85. Züchner S, Mersiyanova IV, Muglia M, Bissar-Tadmouri N, Rochelle J, Dadali EL, et al. Mutations in the mitochondrial GTPase mitofusin 2 cause Charcot-Marie-Tooth neuropathy type 2A. Nat Genet. 2004;36:449-51.

86. Ouvrier R, Grew S. Mechanisms of disease and clinical features of mutations of the gene for mitofusin 2: An important cause of hereditary peripheral neuropathy with striking clinical variability in children and adults. Dev Med Child Neurol. 2010;52:328-30.

87. Gowrisankaran S, Anastasakis A, Fishman GA, Alexander KR. Structural and functional measures of inner retinal integrity following visual acuity improvement in a patient with hereditary motor and sensory neuropathy type VI. Ophthalmic Genet. 2011;32:188-92.

88. Carroll WM, Jones SJ, Halliday AM. Visual evoked potential abnormalities in Charcot-Marie-Tooth disease and comparison with Friedreich's ataxia. J Neurol Sci. 1983;61:123-33.

89. Triantafyllou N, Rombos A, Athanasopoulou H, Siafakas A, Loulakaki SM. Electrophysiological study (EEG, VEPs, BAEPs) in patients with Charcot Marie Tooth (type HMSN I) disease. Electromyogr Clin Neurophysiol. 1989;29:259-63.

90. Bähr M, Andres F, Timmerman V, Nelis ME, van Broeckhoven C, Dichgans J. Central visual, acoustic, and motor pathway involvement in a Charcot-Marie-Tooth family with an Asn205Ser mutation in the connexin 32 gene. J Neurol Neurosurg Psychiatry. 1999;66:202-6.

91. Botsford B, Vuong LN, Hedges TR, Mendoza-Santiesteban CE. Characterization of Charcot-Marie-Tooth optic neuropathy. J Neurol. 2017;264:2431-5.

92. Thompson DA, Feather S, Stanescu HC, Freudenthal B, Zdebik AA, Warth R, et al. Altered electroretinograms in patients with KCNJ10 mutations and EAST syndrome. J Physiol. 2011;589:1681-9.

93. Bockenhauer D, Feather S, Stanescu HC, Bandulik S, Zdebik AA, Reichold M, et al. Epilepsy, Ataxia, Sensorineural Deafness, Tubulopathy, and KCNJ10 Mutations. N Engl J Med. 2009;360:1960-70.

94. Kofuji P, Ceelen P, Zahs KR, Surbeck LW, Lester HA, Newman EA. Genetic inactivation of an inwardly rectifying potassium channel (kir4.1 Subunit) in mice: Phenotypic impact in retina. J Neurosci. 2000;20:5733-40.

95. Raz-Prag D, Grimes WN, Fariss RN, Vijayasarathy C, Campos $\mathrm{MM}$, Bush RA, et al. Probing potassium channel function in vivo by intracellular delivery of antibodies in a rat model of retinal neurodegeneration. Proc Natl Acad Sci USA. 2010;107:12710-5.

96. Vaughan HG, Katzman R, Taylor J. Alterations of visual evoked response in the presence of homonymous visual defects. Electroencephalogr Clin Neurophysiol. 1963;15:737-46.

97. Kooi KA, Yamada T, Marshall RE. Field studies of monocularly evoked cerebral potentials in bitemporal hemianopsia. Neurology. 1973;23:1217-25.

98. Holder GE. The effects of chiasmal compression on the pattern visual evoked potential. Electroencephalogr Clin Neurophysiol. 1978;45:278-80.

99. Fisher NF, Jampolsky A, Scott AB, Morris A, Lehmann D, Alden J. Traumatic bitemporal hemianopsia. Part III. Nasal versus temporal retinal function. Am J Ophthalmol. 1968;65:578-81.

100. Kriss A, Russell-Eggitt I, Harris CM, Lloyd IC, Taylor D. Aspects of albinism. Ophthalmic Paediatr Genet. 1992;13:89-100.

101. Dorey SE, Neveu MM, Burton LC, Sloper JJ, Holder GE. The clinical features of albinism and their correlation with visual evoked potentials. Br J Ophthalmol. 2003;87:767-72.

102. Vaughan HG, Katzman R. Evoked response in visual disorders. Ann N Y Acad Sci. 2006;112:305-19.

103. Galkina NS, Gnezditskii VV, Aleksandrova AA, Kozlova AI. Investigation of evoked potentials to photic stimulation in man after deafferentation of the visual cortex. Biull Eksp Biol Med. 1975;79:371-4.

104. Blumhardt LD, Halliday AM. Cortical Abnormalities and the Visual Evoked Response. In: Spekreijse H, Apkarian PA, editors. Visual Pathways. Doc Ophthalmol Proceedings Series. Vol. 27. Dordrecht: Springer; 1981. p. 347-65.

105. Celesia GG, Meredith JT, Pluff K. Perimetry, visual evoked potentials and visual evoked spectrum array in homonymous hemianopsia. Electroencephalogr Clin Neurophysiol. 1983;56:16-30.

106. Halliday AM, Halliday E, Kriss A, Mcdonald WI, Mushin J. The pattern-evoked potential in compression of the anterior visual pathways. Brain. 1976;99:357-74.

107. Brecelj JA. VEP study of the visual pathway function in compressive lesions of the optic chiasm. Full-field versus half-field stimulation. Electroencephalogr Clin Neurophysiol. 1992;84:209-18.

108. Barrett G, Blumhardt L, Halliday AM, Halliday E, Kriss A. A paradox in the lateralisation of the visual evoked response. Nature. 1976;261:253-5.

109. Marmoy OR, Handley SE, Thompson DA. Pattern-onset and OFFset visual evoked potentials in the diagnosis of hemianopic field defects. Doc Ophthalmol. 2021;142:165-76.

110. Gott PS, Weiss MH, Apuzzo M, van der Meulen JP. Checkerboard visual evoked response in evaluation and management of pituitary tumors. Neurosurgery. 1979;5:553-8.

111. Müller-Jensen A, Zschocke S, Dannheim F. VER analysis of the chiasmal syndrome. J Neurol. 1981;225:33-40.

112. Groswasser Z, Kriss A, Halliday AM, McDonald WI. Patternand flash-evoked potentials in the assessment and management of optic nerve gliomas. J Neurol Neurosurg Psychiatry. 1985;48:1125-34.

113. Wenzel D, Brandl U, Beck JD, Cedzich C, Albert F. Visual evoked potentials in tumors from orbita to occipital lobe in childhood. Neurosurg Rev. 1988;11:279-86.

114. Feinsod M, Selhorst JB, Hoyt WF, Wilson CB. Monitoring optic nerve function during craniotomy. J Neurosurg. 1976;44:29-31.

115. Flanagan JG, Harding GFA. Multi-channel visual evoked potentials in early compressive lesions of the chiasm. Doc Ophthalmol. 1988;69:271-81.

116. Kupersmith MJ, Siegel IM, Carr RE, Ransohoff J, Flamm E, Shakin E. Visual Evoked Potentials in Chiasmal Gliomas in Four Adults. Arch Neurol. 1981;38:362-5.

117. Kelly JP, Leary S, Khanna P, Weiss AH. Longitudinal measures of visual function, tumor volume, and prediction of visual outcomes after treatment of optic pathway gliomas. Ophthalmology. 2012;119:1231-7.

118. van Mierlo C, Spileers W, Legius E, Casteels I, Cassiman C. Role of visual evoked potentials in the assessment and management of optic pathway gliomas in children. Doc Ophthalmol. 2013;127:177-90.

119. Dotto P, de F, Berezovsky A, Cappellano AM, da Silva NS, Sacai PY, Silva FAB, et al. Visual function assessed by visually evoked potentials in optic pathway low-grade gliomas with and 
without neurofibromatosis type 1. Doc Ophthalmol. 2018;136:177-89.

120. Kelly JP, Weiss AH. Comparison of Pattern Visual-Evoked Potentials to Perimetry in the Detection of Visual Loss In Children With Optic Pathway Gliomas. J AAPOS. 2006;10:298-306.

121. Wolsey DH, Larson SA, Creel D, Hoffman R. Can Screening for Optic Nerve Gliomas in Patients With Neurofibromatosis Type I Be Performed With Visual-Evoked Potential Testing? J AAPOS. 2006;10:307-11.

122. Holder GE. The pattern electroretinogram in anterior visual pathway dysfunction and its relationship to the pattern visual evoked potential: a personal clinical review of 743 eyes. Eye. 1997;11:924-34.

123. Danesh-Meyer HV, Carroll SC, Gaskin BJ, Gao A, Gamble GD. Correlation of the multifocal visual evoked potential and standard automated perimetry in compressive optic neuropathies. Investig Ophthalmol Vis Sci. 2006;47:1458-63.

124. Semela L, Yang EB, Hedges TR, Vuong L, Odel JG, Hood DC. Multifocal visual-evoked potential in unilateral compressive optic neuropathy. Br J Ophthalmol. 2007;91:445-8.

125. Jayaraman M, Ambika S, Gandhi RA, Bassi SR, Ravi P, Sen P. Multifocal visual evoked potential recordings in compressive optic neuropathy secondary to pituitary adenoma. Doc Ophthalmol. 2010;121:197-204.

126. Sousa RM, Oyamada MK, Cunha LP, Monteiro MLR. Multifocal visual evoked potential in eyes with temporal hemianopia from chiasmal compression: correlation with standard automated perimetry and OCT findings. Investig Ophthalmol Vis Sci. 2017;58:4436-46.

127. Parmar DN, Sofat A, Bowman R, Barlett JR, Holder GE. Visual prognostic value of the pattern electroretinogram in chiasmal compression. Br J Ophthalmol. 2000;84:1024-6.

128. Rüther K, Ehlich P, Philipp A, Eckstein A, Zrenner E. Prognostic value of the pattern electroretinogram in cases of tumors affecting the optic pathway. Graefes Arch Clin Exp Ophthalmol. 1998;236:259-63.

129. Rangaswamy NV, Frishman LJ, Dorotheo EU, Schiffman JS, Bahrani HM, Tang RA. Photopic ERGs in patients with optic neuropathies: comparison with primate ERGs after pharmacologic blockade of inner retina. Investig Ophthalmol Vis Sci. 2004;45:3827-37.

130. Moon $\mathrm{CH}$, Ahn S, il, Ohn YH, Kwak HW, Park TK. Visual prognostic value of photopic negative response and optical coherence tomography in central retinal vein occlusion after antiVEGF treatment. Doc Ophthalmol. 2013;126:211-9.

131. Moon CH, Hwang SC, Ohn YH, Park TK. The time course of visual field recovery and changes of retinal ganglion cells after optic chiasmal decompression. Investig Ophthalmol Vis Sci. 2011;52:7966-73.

132. Abed E, Piccardi M, Rizzo D, Chiaretti A, Ambrosio L, Petroni $\mathrm{S}$, et al. Functional loss of the inner retina in childhood optic gliomas detected by photopic negative response. Investig Ophthalmol Vis Sci. 2015; 56:2469-74.

133. Genovesi-Ebert F, di Bartolo E, Lepri A, Poggi V, Romani A, Nardi M. Standardized echography, pattern electroretinography and visual-evoked potential and automated perimetry in the early diagnosis of Graves' neuropathy. Ophthalmologica. 1998;212 (supp 1):101-3.

134. Spadea L. Early detection of P-VEP and PERG changes in opthalmic Graves' disease. Graefes Arch Clin Exp Ophthalmol. 1997;235:501-5.

135. Przemysław P, Janusz M, Alina BL, Maria G. Pattern electroretinogram (PERG) in the early diagnosis of optic nerve dysfunction in the course of Graves' orbitopathy. Klinika Ocz. 2013;115:9-12.
136. Mitchell KW, Wood CM, Howe JW. Pattern visual evoked potentials in hyperthyroidism. Br J Ophthalmol. 1988;72:534-7.

137. Wijngaarde R, van Lith GHM. Pattern EPs in endocrine orbitopathy. Doc Ophthalmol. 1980;48:327-32.

138. Salvi M, Spaggiari E, Neri F, Macaluso C, Gardini E, Ferrozzi F, et al. The Study of Visual Evoked Potentials in Patients with Thyroid-Associated Ophthalmopathy Identifies Asymptomatic Optic Nerve Involvement. J Clin Endocrinol Metab. 1997;82:1027-30.

139. Ambrosio G, Ferrara G, Vitale R, de Marco R. Visual evoked potentials in patients with Graves' ophthalmopathy complicated by ocular hypertension and suspect glaucoma or dysthyroid optic neuropathy. Doc Ophthalmol. 2003;106:99-104.

140. Iao TWU, Rong SS, Ling AN, Brelén ME, Young AL, Chong KKL. Electrophysiological Studies in Thyroid Associated Orbitopathy: a Systematic Review. Sci Rep. 2017;7:12108.

141. Lipski A, Eckstein A, Esser J, Loesch C, Mann K, Mohr C, et al. Course of pattern-reversed visual evoked cortical potentials in 30 eyes after bony orbital decompression in dysthyroid optic neuropathy. Br J Ophthalmol. 2011;95:222-6.

142. Kobayashi A, Ando A, Tagami N, Kitagawa M, Kawai E, Akioka M, et al. Severe optic neuropathy caused by dichloromethane inhalation. J Ocul Pharm Ther. 2008;24:607-12.

143. Allen D, Riordan-Eva P, Paterson RW, Hadden RDM. Subacute peripheral and optic neuropathy syndrome with no evidence of a toxic or nutritional cause. Clin Neurol Neurosurg. 2013;115:1389-93.

144. Grillo LM, Nguyen HV, Tsang SH, Hood DC, Odel JG. Cobaltchromium metallosis with normal electroretinogram. J Neuroophthalmol. 2016;36:383-8.

145. Mhéalóid ÁNí, Cunniffe G. Optic neuritis secondary to antiandrogen therapy. Ir J Med Sci. 2017;186:565-70.

146. Petrera JE, Fledelius HC, Trojaborg W. Serial pattern evoked potential recording in a case of toxic optic neuropathy due to ethambutol. Electroencephalogr Clin Neurophysiol. 1988;71:146-9.

147. Nurieva O, Hubacek JA, Urban P, Hlusicka J, Diblik P, Kuthan $\mathrm{P}$, et al. Clinical and genetic determinants of chronic visual pathway changes after methanol - induced optic neuropathy: four-year follow-up study. Clin Toxicol. 2019;57:387-97.

148. Simmons IG, Good PA. Carbon monoxide poisoning causes optic neuropathy. Eye. 1998;12:809-14.

149. Venkatramani DV, Goel S, Ratra V, Gandhi RA. Toxic optic neuropathy following ingestion of homeopathic medication Arnica-30. Cutan Ocul Toxicol. 2013;32:95-7.

150. Fabian RH, Norcross KA, Hancock MB. Surfer's Neuropathy. N Engl J Med. 1987;316:555.

151. Mahapatra AK. Visual evoked potentials in optic nerve injury. Does it merit a mention? Acta Neurochir. 1991;112:47-9.

152. Mahapatra AK. Delayed recovery from indirect optic nerve injury. A report of two unusual cases. J Neurosurg Sci. 1992;36:151-3.

153. Agarwal A, Mahapatra AK. Visual outcome in optic nerve injury patients without initial light perception. Indian J Ophthalmol. 1999;47:233-6.

154. Tabatabaei SA, Soleimani M, Alizadeh M, Movasat M, Mansoori MR, Alami Z, et al. Predictive value of visual evoked potentials, relative afferent pupillary defect, and orbital fractures in patients with traumatic optic neuropathy. Clin Ophthalmol. 2011;5:1021-6.

155. He Z, Li Q, Yuan J, Zhang X, Gao R, Han Y, et al. Evaluation of transcranial surgical decompression of the optic canal as a treatment option for traumatic optic neuropathy. Clin Neurol Neurosurg. 2015;134:130-5.

156. Nukada $\mathrm{H}$. Ischemia and diabetic neuropathy. In: Handbook of Clinical Neurology. Amsterdam, The Netherlands: Elsevier; 2014. p. 469-87. 
157. Anastasi M, Lauricella M, Giordano C, Galluzzo A. Visual evoked potentials in insulin-dependent diabetics. Acta Diabetol Lat. 1985;22:343-9.

158. Algan M, Ziegler O, Gehin P, Got I, Raspiller A, Weber M, et al. Visual evoked potentials in diabetic patients. Diabetes Care. 1989;12:227-9.

159. Parisi V, Uccioli L, Monticone G, Parisi L, Menzinger G, Bucci MG. Visual evoked potentials after photostress in insulindependent diabetic patients with or without retinopathy. Graefes Arch Clin Exp Ophthalmol. 1994;232:193-8.

160. Parisi V, Uccioli L. Visual electrophysiological responses in persons with type 1 diabetes. Diabetes Metab Res Rev. 2001;17:12-8.

161. Parisi V, Uccioli L, Parisi L, Colacino G, Manni G, Menzinger $\mathrm{G}$, et al. Neural conduction in visual pathways in newlydiagnosed IDDM patients. Electroencephalogr Clin Neurophysiol. 1998;108:490-6.

162. Parisi V, Uccioli L, Monticone G, Parisi L, Manni G, Ippoliti D, et al. Electrophysiological assessment of visual function in IDDM patients. Electroencephalogr Clin Neurophysiol. 1997;104:171-9.

163. Deák K, Fejes I, Janáky M, Várkonyi T, Benedek G, Braunitzer G. Further Evidence for the Utility of Electrophysiological Methods for the Detection of Subclinical Stage Retinal and Optic Nerve Involvement in Diabetes. Med Princ Pr. 2016;25:282-5.

164. Pozzessere G, Rizzo PA, Valle E, Mollica MA, Sanarelli L, Morano S, et al. A longitudinal study of multimodal evoked potentials in diabetes mellitus. Diabetes Res. 1989;10:17-20.

165. Mariani E, Moreo G, Colucci GB. Study of visual evoked potentials in diabetics without retinopathy: correlations with clinical findings and polyneuropathy. Acta Neurol Scand. 1990;81:337-40.

166. Pietravalle P, Morano S, Cristina G, Mancuso M, Valle E, Annulli MA, et al. Early complications in type 1 diabetes: central nervous system alterations precede kidney abnormalities. Diabetes Res Clin Pr. 1993;21:143-54.

167. Dolu H, Ulas UH, Bolu E, Ozkardes A, Odabasi Z, Ozata M, et al. Evaluation of central neuropathy in type II diabetes mellitus by multimodal evoked potentials. Acta Neurol Belg. 2003;103:206-11.

168. Arden GB, Hamilton AMP, Wilson-Holt J, Ryan S, Yudkin JS, Kurtz A. Pattern electroretinograms become abnormal when background diabetic retinopathy deteriorates to a preproliferative stage: possible use as a screening test. $\mathrm{Br} \mathrm{J}$ Ophthalmol. 1986;70:330-5.

169. Ryan S, Arden GB. Electrophysiological discrimination between retinal and optic nerve disorders. Doc Ophthalmol. 1988;68:247-55.

170. Falsini B, Porciatti V, Scalia G, Caputo S, Minnella A, di Leo MAS, et al. Steady-state pattern electroretinogram in insulindependent diabetics with no or minimal retinopathy. Doc Ophthalmol. 1989;73:193-200.

171. Park JC, Chau FY, Lim JI, McAnany JJ. Electrophysiological and pupillometric measures of inner retina function in nonproliferative diabetic retinopathy. Doc Ophthalmol. 2019;139:99-111.

172. Kizawa J, Machida S, Kobayashi T, Gotoh Y, Kurosaka D. Changes of oscillatory potentials and photopic negative response in patients with early diabetic retinopathy. Jpn J Ophthalmol. 2006;50:367-73.

173. Chen H, Zhang M, Huang S, Wu D. The photopic negative response of flash ERG in nonproliferative diabetic retinopathy. Doc Ophthalmol. 2008;117:129-35.

174. Kim HD, Park JY, Ohn YH. Clinical applications of photopic negative response $(\mathrm{PhNR})$ for the treatment of glaucoma and diabetic retinopathy. Korean J Ophthalmol. 2010;24:89-95.
175. McFarlane M, Wright T, Stephens D, Nilsson J, Westall CA. Blue flash ERG PhNR changes associated with poor long-term glycemic control in adolescents with type 1 diabetes. Investig Ophthalmol Vis Sci. 2012;53:741-8.

176. Aylward GW. The scotopic threshold response in diabetic retinopathy. Eye. 1989;3:626-37.

177. Machida S, Gotoh Y, Tanaka M, Tazawa Y. Predominant loss of the photopic negative response in central retinal artery occlusion. Am J Ophthalmol. 2004;137:938-40.

178. Chen $\mathrm{H}, \mathrm{Wu} \mathrm{D}$, Huang $\mathrm{S}$, Yan $\mathrm{H}$. The photopic negative response of the flash electroretinogram in retinal vein occlusion. Doc Ophthalmol. 2006;113:53-9.

179. Shinoda K, Yamada K, Matsumoto CS, Kimoto K, Nakatsuka K. Changes in retinal thickness are correlated with alterations of electroretinogram in eyes with central retinal artery occlusion. Graefes Arch Clin Exp Ophthalmol. 2008;246:949-54.

180. Matsumoto CS, Shinoda K, Yamada K, Nakatsuka K. Photopic negative response reflects severity of ocular circulatory damage after central retinal artery occlusion. Ophthalmologica. 2009;223:362-9.

181. Matsumoto CS, Shinoda K, Nakatsuka K. High correlation of scotopic and photopic electroretinogram components with severity of central retinal artery occlusion. Clin Ophthalmol. 2011;5:115-21.

182. Ogino K, Tsujikawa A, Nakamura H, Miyamoto K, Murakami T, Muraoka Y, et al. Focal macular electroretinogram in macular edema secondary to central retinal vein occlusion. Investig Ophthalmol Vis Sci. 2011;52:3514-20.

183. Ogino K, Tsujikawa A, Murakami T, Muraoka Y, AkagiKurashige Y, Ishihara $\mathrm{K}$, et al. Evaluation of macular function using focal macular electroretinography in eyes with macular edema associated with branch retinal vein occlusion. Investig Ophthalmol Vis Sci. 2011;52:8047-55.

184. Gardašević Topčić I, Šuštar M, Brecelj J, Hawlina M, Jaki, Mekjavić P. Morphological and electrophysiological outcome in prospective intravitreal bevacizumab treatment of macular edema secondary to central retinal vein occlusion. Doc Ophthalmol. 2014;129:27-38.

185. Noma H, Mimura T, Kuse M, Yasuda K, Shimura M. Photopic negative response in branch retinal vein occlusion with macular edema. Int Ophthalmol. 2015;35:19-26.

186. Nishimura T, Machida S, Tada A, Oshida E, Muto T. Macular function following intravitreal ranibizumab for macular edema associated with branch retinal vein occlusion: 12-month results. Doc Ophthalmol. 2020;141:127-36.

187. Nishimura T, Machida S, Tada A, Oshida E, Muto T. Macular function following intravitreal ranibizumab for macular edema associated with branch retinal vein occlusion. Doc Ophthalmol. 2019;139:67-74.

188. Kim HM, Park KH, Woo SJ. Correlation of electroretinography components with visual function and prognosis of central retinal artery occlusion. Sci Rep. 2020;10:12146.

189. Hayreh SS. Ischemic optic neuropathy. Prog Retin Eye Res. 2009;28:34-62.

190. Hayreh SS. Management of ischemic optic neuropathies. Indian J Ophthalmol. 2011;59:123-36.

191. Wilson WB. Visual-evoked response differentiation of ischemic optic neuritis from the optic neuritis of multiple sclerosis. Am J Ophthalmol. 1978;86:530-5.

192. Hennerici M, Wenzel D, Freund HJ. The comparison of smallsize rectangle and checkerboard stimulation for the evaluation of delayed visual evoked responses in patients suspected of multiple sclerosis. Brain. 1977;100:119-36.

193. Ikeda H, Tremain KE, Sanders MD. Neurophysiological investigation in optic nerve disease: combined assessment of the visual evoked response and electroretinogram. Br J Ophthalmol. 1978;62:227-39. 
194. Barbano L, Ziccardi L, Parisi V. Correlations between visual morphological, electrophysiological, and acuity changes in chronic non-arteritic ischemic optic neuropathy. Graefes Arch Clin Exp Ophthalmol. 2021;259:1297-308.

195. Parisi V, Gallinaro G, Ziccardi L, Coppola G. Electrophysiological assessment of visual function in patients with non-arteritic ischaemic optic neuropathy. Eur J Neurol. 2008;15:839-45.

196. Brudet-Wickel CLM, van Lith GHM. Electrophysiology in acute anterior ischaemic optic neuropathy. Ophthalmologica. 1984;188:111-7.

197. Thompson PD, Mastaglia FL, Carroll WM. Anterior ischaemic optic neuropathy. A correlative clinical and visual evoked potential study of 18 patients. J Neurol Neurosurg Psychiatry. 1986;49:128-35.

198. Wildberger H. Neuropathies of the optic nerve and visual evoked potentials with special reference to color vision and differential light threshold measured with the computer perimeter OCTOPUS. Doc Ophthalmol. 1984;58:147-227.

199. Holder GE. The Visual Evoked Potential in Ischaemic Optic Neuropathy. In: Spekreijse H, Apkarian PA, editors. Visual Pathways. Documenta Ophthalmologica Proceedings Series. Vol. 27. Dordecht: Springer;1981. p. 123-9.

200. Cox TA, Stanley Thompson H, Hayreh SS, Snyder JE. Visual Evoked Potential and Pupillary Signs: a Comparison in Optic Nerve Disease. Arch Ophthalmol. 1982;100:1603-7.

201. Atilla H, Tekeli O, Örnek K, Batioglu F, Elhan AH, Eryilmaz T. Pattern electroretinography and visual evoked potentials in optic nerve diseases. J Clin Neurosci. 2006;13:55-9.

202. Janáky M, Fülöp Z, Pálffy A, Benedek K, Benedek G. Electrophysiological findings in patients with nonarteritic anterior ischemic optic neuropathy. Clin Neurophysiol. 2006;117:1158-66.

203. Froehlich J, Kaufman DI. Use of pattern electroretinography to differentiate acute optic neuritis from acute anterior ischemic optic neuropathy. Electroencephalogr Clin Neurophysiol. 1994;92:480-6.

204. Tamada K, MacHida S, Yokoyama D, Kurosaka D. Photopic negative response of full-field and focal macular electroretinograms in patients with optic nerve atrophy. Jpn J Ophthalmol. 2009;53:608-14.

205. Okuno T, Kida T, Ikeda T, Oku H. Significant correlations between photopic negative response, afferent pupillary defect, and mean defects of visual fields in asymmetric optic nerve disorders. Graefes Arch Clin Exp Ophthalmol. 2020;258:1821-7.

206. Tormene AP, Doro D. Electrophysiological findings in anterior ischemic optic neuropathy. Metab Pediatr Syst Ophthalmol. 1985;12:76-9.

207. Hood DC, Greenstein VC, Odel JG, Zhang X, Ritch R, Liebmann JM, et al. Visual field defects and multifocal visual evoked potentials: Evidence of a linear relationship. Arch Ophthalmol. 2002;120:1672-81.

208. Jayaraman M, Gandhi RA, Ravi P, Sen P. Multifocal visual evoked potential in optic neuritis, ischemic optic neuropathy and compressive optic neuropathy. Indian J Ophthalmol. 2014;62:299-304.

209. Petzold A, Wattjes MP, Costello F, Flores-Rivera J, Fraser CL, Fujihara K, et al. The investigation of acute optic neuritis: a review and proposed protocol. Nat Rev Neurol. 2014;10:447-58.

210. Percy AK, Nobrega FT, Kurland LT. Optic Neuritis and Multiple Sclerosis: an Epidemiologic Study. Arch Ophthalmol. 1972;87:135-9.

211. Halliday AM, McDonald WI, Mushin J. Visual evoked response in diagnosis of multiple sclerosis. Br Med J. 1973;4:661-4.

212. Sisto D, Trojano M, Vetrugno M, Trabucco T, Iliceto G, Sborgia C. Subclinical visual involvement in multiple sclerosis: a study by MRI, VEPs, frequency-doubling perimetry, standard perimetry, and contrast sensitivity. Investig Ophthalmol Vis Sci. $2005 ; 46: 1264-8$.
213. Janáky M, Jánossy, Horváth G, Benedek G, Braunitzer G. VEP and PERG in patients with multiple sclerosis, with and without a history of optic neuritis. Doc Ophthalmol. 2017;134:185-93.

214. Halliday AM, Mcdonald WI, Mushin J. Delayed visual evoked response in optic neuritis. Lancet. 1972;1:982-5.

215. Frederiksen JL, Petrera J. Serial visual evoked potentials in 90 untreated patients with acute optic neuritis. Surv Ophthalmol. 1999;44(supp 1):S54-62.

216. Brusa A, Jones SJ, Kapoor R, Miller DH, Plant GT. Long-term recovery and fellow eye deterioration after optic neuritis, determined by serial visual evoked potentials. J Neurol. 1999;246:776-82.

217. Brusa A, Jones SJ, Plant GT. Long-term remyelination after optic neuritis: a 2-year visual evoked potential and psychophysical serial study. Brain. 2001;124:468-79.

218. Yang EB, Hood DC, Rodarte C, Zhang X, Odel JG, Behrens MM. Improvement in conduction velocity after optic neuritis measured with the multifocal VEP. Investig Ophthalmol Vis Sci. 2007;48:692-8.

219. Hidajat RR, Goode DH. Normalisation of visual evoked potentials after optic neuritis. Doc Ophthalmol. 2003;106:305-9.

220. Celesia GG, Kaufman DI, Brigell M, Toleikis S, Kokinakis D, Lorance R, et al. Optic neuritis: a prospective study. Neurology. 1990;40:919-23.

221. Tekavčič-Pompe M, Stirn-Kranjc B, Brecelj J. Optic neuritis in children - Clinical and electrophysiological follow-up. Doc Ophthalmol. 2003;107:261-70.

222. Holder GE. The incidence of abnormal pattern electroretinography in optic nerve demyelination. Electroencephalogr Clin Neurophysiol. 1991;78:18-26.

223. Kaufman DI, Lorance RW, Woods M, Wray SH. The pattern electroretinogram: a long-term study in acute optic neuropathy. Neurology. 1988;38:1767-74.

224. Froehlich J, Kaufman DI. The pattern electroretinogram: N95 amplitudes in normal subjects and optic neuritis patients. Electroencephalogr Clin Neurophysiol. 1993;88:83-91.

225. Parisi V, Manni G, Spadaro M, Colacino G, Restuccia R, Marchi $\mathrm{S}$, et al. Correlation between Morphological and Functional Retinal Impairment in Multiple Sclerosis Patients. Investig Ophthalmol Vis Sci. 1999;40:2520-7.

226. Rodriguez-Mena D, Almarcegui C, Dolz I, Herrero R, Bambo MP, Fernandez J, et al. Electrophysiologic evaluation of the visual pathway in patients with multiple sclerosis. J Clin Neurophysiol. 2013;30:376-81.

227. Berninger TA, Heider W. Pattern electroretinograms in optic neuritis during the acute stage and after remission. Graefes Arch Clin Exp Ophthalmol. 1990;228:410-4.

228. Wang J, Cheng H, Hu YS, Tang RA, Frishman LJ. The photopic negative response of the flash electroretinogram in multiple sclerosis. Investig Ophthalmol Vis Sci. 2012;53:1315-23.

229. Gotoh Y, Machida S, Tazawa Y. Selective Loss of the Photopic Negative Response in Patients with Optic Nerve Atrophy. Arch Ophthalmol. 2004;122:341-6.

230. Klistorner A, Arvind H, Garrick R, Graham SL, Paine M, Yiannikas C. Interrelationship of optical coherence tomography and multifocal visual-evoked potentials after optic neuritis. Investig Ophthalmol Vis Sci. 2010;51:2770-7.

231. Pihl-Jensen G, Schmidt MF, Frederiksen JL. Multifocal visual evoked potentials in optic neuritis and multiple sclerosis: a review. Clin Neurophysiol. 2017;128:1234-45.

232. Hayreh SS. Pathogenesis of optic disc edema in raised intracranial pressure. Vol. 50. Prog Retin Eye Res. 2016;50:108-44.

233. Rowe FJ. Assessment of visual function in idiopathic intracranial hypertension. Br J Neurosurg. 2011;25:45-54.

234. York D, Legan M, Benner S, Watts C. Further studies with a noninvasive method of intracranial pressure estimation. Neurosurgery. 1984;14:456-61. 
235. York DH, Pulliam MW, Rosenfeld JG, Watts C. Relationship between visual evoked potentials and intracranial pressure. J Neurosurg. 1981;55:909-16.

236. Coupland SG, Cochrane DD. Visual evoked potentials, intracranial pressure and ventricular size in hydrocephalus. Doc Ophthalmol. 1987;66:321-9.

237. Krogsaa B, Sørensen PS, Seedorff HH, Trojaborg W, Gjerris F. Ophthalmologic prognosis in Benign Intracranial Hypertension. Acta Ophthalmol. 2009;63:62-4.

238. Sørensen PS, Trojaborg W, Gjerris F, Krogsaa B. Visual Evoked Potentials in Pseudotumor Cerebri. Arch Neurol. 1985;42:150-3.

239. Hamamci M, Tombul T. Visual evoked potentials follow-up in idiopathic intracranial hypertension. Neurosciences. 2019;24:185-91.

240. Kesler A, Vakhapova V, Korczyn AD, Drory VE. Visual evoked potentials in idiopathic intracranial hypertension. Clin Neurol Neurosurg. 2009;111:433-6.

241. Mustafa YH, Elbarbary H, El-Refaaey M, El-Azhary R. Visual Evoked Potential in Idiopathic Intracranial Hypertension. J Clin Exp Ophthalmol. 2019;10:1-3.

242. Takkar A, Goyal MK, Bansal R, Lal V. Clinical and Neuroophthalmologic Predictors of Visual Outcome in Idiopathic Intracranial Hypertension. Neuroophthalmology. 2018;42:201-8

243. Thompson DA, Liasis A, Hardy S, Hagan R, Hayward RD, Evans RD, et al. Prevalence of abnormal pattern reversal visual evoked potentials in craniosynostosis. Plast Reconstr Surg. 2006;118:184-92.

244. Haredy MM, Liasis A, Davis A, Koesarie K, Fu V, Losee JE, et al. Serial, Visually-Evoked Potentials for the Assessment of
Visual Function in Patients with Craniosynostosis. J Clin Med. 2019;8:1555.

245. Haredy MM, Liasis A, Fu V, Davis A, Pollack IF, Losee JE, et al. Serial Visual Evoked Potentials in Patients with Craniosynostosis and Invasive Intracranial Pressure Monitoring. Plast Reconstr Surg. 2019;144:446e-52e.

246. Liasis A, Nischal KK, Walters B, Thompson D, Hardy S, Towell $\mathrm{A}$, et al. Monitoring visual function in children with syndromic craniosynostosis: a comparison of 3 methods. Arch Ophthalmol. 2006;124:1119-26.

247. Falsini B, Tamburrelli C, Porciatti V, Anile C, Porrello G, Mangiola N. Pattern electroretinograms and visual evoked potentials in idiopathic intracranial hypertension. Ophthalmologica. 1992;205:194-203.

248. Solomon SG, Peirce JW, Dhruv NT, Lennie P. Profound contrast adaptation early in the visual pathway. Neuron. 2004;42:155-62.

249. Heinrich TS, Bach M. Contrast adaptation in human retina and cortex. Investig Ophthalmol Vis Sci. 2001;42:2721-7.

250. Afonso CL, Raza AS, Kreuz AC, Hokazono K, Cunha LP, Oyamada MK, et al. Relationship between pattern electroretinogram, frequency-domain OCT, and automated perimetry in chronic papilledema from pseudotumor cerebri syndrome. Investig Ophthalmol Vis Sci. 2015;56:3656-65.

251. Moss HE, Park JC, McAnany JJ. The photopic negative response in idiopathic intracranial hypertension. Investig Ophthalmol Vis Sci. 2015;56:3709-14.

252. Park JC, Moss HE, McAnany JJ. Electroretinography in idiopathic intracranial hypertension: comparison of the pattern ERG and the photopic negative response. Doc Ophthalmol. 2018;136:45-55. 